IZA DP No. 9446

Competitiveness and the Gender Gap among Young Business Professionals

Ernesto Reuben

Paola Sapienza

Luigi Zingales

October 2015 


\title{
Competitiveness and the Gender Gap among Young Business Professionals
}

\author{
Ernesto Reuben \\ Columbia University \\ and IZA
}

Paola Sapienza

Northwestern University

Luigi Zingales

University of Chicago

\section{Discussion Paper No. 9446 \\ October 2015}

\author{
IZA \\ P.O. Box 7240 \\ 53072 Bonn \\ Germany \\ Phone: +49-228-3894-0 \\ Fax: +49-228-3894-180 \\ E-mail: iza@iza.org
}

\begin{abstract}
Any opinions expressed here are those of the author(s) and not those of IZA. Research published in this series may include views on policy, but the institute itself takes no institutional policy positions. The IZA research network is committed to the IZA Guiding Principles of Research Integrity.

The Institute for the Study of Labor (IZA) in Bonn is a local and virtual international research center and a place of communication between science, politics and business. IZA is an independent nonprofit organization supported by Deutsche Post Foundation. The center is associated with the University of Bonn and offers a stimulating research environment through its international network, workshops and conferences, data service, project support, research visits and doctoral program. IZA engages in (i) original and internationally competitive research in all fields of labor economics, (ii) development of policy concepts, and (iii) dissemination of research results and concepts to the interested public.
\end{abstract}

IZA Discussion Papers often represent preliminary work and are circulated to encourage discussion. Citation of such a paper should account for its provisional character. A revised version may be available directly from the author. 


\section{ABSTRACT}

\section{Competitiveness and the Gender Gap among Young Business Professionals ${ }^{*}$}

Important gender differences in earnings and career trajectories persist. Particularly, in professions such as business. Gender differences in competitiveness have been proposed as a potential explanation. Using an incentivized measure of competitiveness, this paper investigates whether competitiveness explains future gender differences in earnings and industry choice in a sample of high-ability MBA graduates. We find that competitive individuals earn $9 \%$ more than their less competitive counterparts do. Moreover, gender differences in competitiveness explain around $10 \%$ of the overall gender gap. We also find that competitive individuals are more likely to work in high-paying industries nine years later, which suggests that the relation between competitiveness and earnings persists in the long run. Lastly, we find that the competitiveness gap in industry emerges over time when MBAs and firms interact with each other.

JEL Classification: J16, D81, D84, I21, C93

Keywords: gender gap, gender differences, competitiveness, business career

Corresponding author:

Ernesto Reuben

Columbia Business School

3022 Broadway

Uris Hall

New York, NY 10027

USA

E-mail: ereuben@columbia.edu

\footnotetext{
* We thank the Templeton Foundation for financial support. We are also thankful for the comments we received from Muriel Niederle, Anne Preston, Christian Traxler, and Roel van Veldhuizen.
} 


\section{Introduction}

Important differences in the choices and resulting labor market outcomes of men and women exist (Bertrand, 2011). Particularly prominent are the gender differences in compensation and representation in the highest paid jobs (e.g., Azmat, Güell, and Manning, 2004; Arulampalam, Booth, and Bryan, 2007). At the top of the corporate ladder, for example, women represented only $6.5 \%$ of the best-paid CEOs in 2014 and were paid 9.9\% less than their male counterparts (Equilar, 2015). ${ }^{1}$ While our understanding of such gender differences has improved substantially, sizeable differences remain unaccounted for (Black et al., 2008; Blau, 2012). A promising explanation for these residual differences is the well-documented gender difference in competitiveness: men are too willing to compete while women shy away from competition (Niederle and Vesterlund, 2011). In this paper, we test this conjecture by evaluating whether the laboratory measure of competitiveness introduced by Niederle and Vesterlund (2007) helps explain future gender differences in earnings and labor market choices in a sample of high-ability business professionals.

The participants of our study consist of individuals who obtained a master's degree in business administration (MBA) from one of the top business schools in the United States-the Booth School of Business of the University of Chicago. This is an interesting group of people to study because top business positions is precisely one of the areas where noticeable gender differences persist, a fact that is often reported by the national media. Our sample of MBAs are potentially influential individuals in the world of business and likely candidates for such positions in the future. We collected data about our sample of MBAs from four different sources: (i) a laboratory experiment and survey questionnaire, which we use to obtain an incentivized measure competitiveness as well as measures of other important psychological traits; (ii) admissions data from the business school, which contains a rich set of demographic characteristics as well as standard measures of academic achievement; (iii) data from the business school's career services office, which includes the participants' earnings in their first job after graduation, the industry participants choose to work in,

\footnotetext{
1 Similarly, Bertrand and Hallock (2001) report that only 2.5\% of the highest paid executives in S\&P 500 firms are women and Wolfers (2006) shows that, from 1992 to 2004, the CEO of an S\&P 1500 firm was a woman only $1.3 \%$ of the time.
} 
and various variables concerning the participants' job search; and (iv) data obtained by tracking participants seven years after they graduated to observe their career progression.

Our data on labor market outcomes displays two important gender differences. First, we find a meaningful gender gap in earnings at graduation: compared to male MBAs, on average, female MBAs earn 15\% less (around \$26k less per year). Second, we find that men and women self-select into different industries and this difference persists several years after graduation. More specifically, female MBAs are 8\% more likely to work in low-paying industries at graduation and $12 \%$ more likely to work in such industries seven years later. We focus on two effects throughout the paper. First, we investigate the relationship between competitiveness, earnings, and industry selection. Second, we evaluate whether competitiveness helps us explain the observed gender differences in earnings and industry selection.

To measure competitiveness, we use the experimental design of Niederle and Vesterlund (2007). It consists of giving participants the opportunity to earn money by answering simple arithmetic problems under two different incentive schemes: piece-rate pay and tournament pay. ${ }^{2}$ Under piecerate pay, participants do not compete with others and simply earn $\$ 4$ per correct answer. Under tournament pay, participants compete with three other randomly chosen participants and earn \$16 per correct answer if they have the highest performance in their group. The participants' willingness to compete is assessed by letting them choose between performing under piece-rate pay or under tournament pay. When they make their choice, participants have no information concerning the performance of others. Like many in the literature, we find that men are twice as likely as women to choose tournament pay (see Niederle and Vesterlund, 2011). The participants' mathematical ability, their beliefs about relative performance, and their risk preferences explains some but not all of the gender difference in choosing tournament pay. As Buser, Niederle, and Oosterbeek (2014) and

\footnotetext{
2 Since we study a setting (business) that is stereotypically male, we elicit competitiveness using a task in an area (math) that is typically associated with men (Reuben, Sapienza, and Zingales, 2014). Experiments using this task in various subject pools have consistently found that men choose tournament pay more often than women (e.g., Niederle and Vesterlund, 2007; Cason, Masters, and Sheremeta, 2010; Healy and Pate, 2011; Balafoutas and Sutter, 2012; Niederle, Segal, and Vesterlund, 2013). That being said, gender differences in competitiveness are sometimes diminished when measured with stereotypically female tasks (e.g., Kamas and Preston 2010; Dreber, von Essen, and Ranehill, 2014; Wozniak, Harbaugh, and Mayr, 2014).
} 
Reuben, Wiswall, and Zafar (2015), we use the decision to perform under tournament pay controlling for ability, beliefs, and risk preferences as a measure of competitiveness.

We obtain our first results by regressing the participants' earnings on their gender, competitiveness, and a large set of control variables. We find that individuals who were classified as competitive in a laboratory experiment two years before earn 9 log points more than their less competitive counterparts (around \$15k more per year), a sizeable effect comparable in magnitude to the effect of gender. In addition, we find that the gender difference in competitiveness accounts for around $10 \%$ of the gender difference in earnings. To put this result in perspective, the sole measure of competitiveness explains half as much of the gender gap in earnings as a rich set of variables that include demographic characteristics, academic performance, and experimental and survey measures of important psychological attributes. Importantly, the experimental measure of competitiveness is not strongly correlated with the large set of control variables, and therefore, it accounts for variance in earnings and in the gender gap that would otherwise remain unexplained.

Our second set of results relate to the relationship between competitiveness and the industry participants work in. This is an important relationship because industry has been shown to be a strong determinant of earnings and of the gender gap among business professionals in the long run (Bertrand, Goldin, and Katz, 2010). Even though there is no relation between competitiveness and industry before participants started their MBA, we find that competitiveness is a good predictor of the industry participants' work in at graduation, and remarkably, it remains a significant predictor of industry several years later. Specifically, we find that competitive individuals are more likely to start and keep working in consulting and to a lesser extent finance instead of other lower-paying industries. This finding suggests that the relation between competitiveness and earnings that we observe at the beginning of the participants' business careers persists in the long run.

An advantage of our dataset is that we obtained information regarding the recruitment process, and therefore, we can observe the stages of the job market in which competitiveness plays a role. In particular, we have information that captures the employers' interests (who they invite for interviews), the job candidates' interests (to which firms they bid for interviews), and the success of job candidates in obtaining internships and transforming them into permanent jobs. We find that competitiveness predicts industry selection when securing and converting internships into 
permanent jobs but not during the interview process. In other words, it appears that meaningful contact between participants and firms is crucial for the emergence of the competitiveness gap in industry selection.

The rest of the paper is organized as follows. In Section 2 we provide an overview of the related literature. In Section 3, we describe the various sources from which we collect our data. In section 4 we present descriptive statistics of our sample, and then, in section 5, we test whether there are gender differences in competitiveness. In sections 6 and 7, we present our main results. Section 6 evaluates the link between competitiveness and earnings while section 7 analyses the relation between competitiveness and selection into different industries. We further discuss our findings and conclude in section 8.

\section{Literature review}

This paper contributes to the growing literature on gender differences in competitiveness (for a review see Niederle and Vesterlund, 2011) and more specifically to studies relating incentivized measures of competitiveness to gender differences in labor market outcomes. Below, we briefly summarize the few studies that fit this description.

The most prominent study in this area is that of Buser, Niederle, and Oosterbeek (2014). In this study, the authors use the same measure of competitiveness we use to predict the educational choices of high school students in the Netherlands. They find that competitive individuals have are around $20 \%$ more likely to select the most prestigious study track, which contains mostly math and science classes, over the least prestigious track, which consists mostly of humanities classes. Moreover, they find that controlling for competitiveness reduces the gender gap in track choice by around $20 \%$. Hence, we extend the findings of Buser, Niederle, and Oosterbeek (2014) by demonstrating that competitiveness predicts actual labor market outcomes in a considerably different sample of participants (our sample is older, better educated, more diverse, and specialized in business). In addition, our finding that competitive individuals gravitate more towards consulting than finance supports Buser, Niederle, and Oosterbeek (2014)'s conjecture that competitiveness is not simply a measure of interest in mathematically-intense fields. 
Kamas and Preston (2015) and Reuben, Wiswall, and Zafar (2015) follow-up on Buser, Niederle, and Oosterbeek (2014)'s work and study whether competitive individuals major in different fields when they complete their undergraduate education in private universities in the United States. A drawback of their evidence, however, is that competitiveness was measured after students chose their major and therefore the causal interpretation of the results is more problematic. Reuben, Wiswall, and Zafar (2015) do not find a relationship between competitiveness and major choice while Kamas and Preston (2015) find that competitive individuals are more likely to major in engineering, natural sciences, and business as opposed to majoring in social sciences or the humanities. In addition to major choice, Kamas and Preston (2015) and Reuben, Wiswall, and Zafar (2015) analyze the relation between competitiveness and self-reported earnings. Reuben, Wiswall, and Zafar (2015) find that competitiveness and confidence measures positively relate with the compensation students expect to earn ten years after graduation. Moreover, they also find that competitiveness helps explain around 18\% of the gender gap in expected earnings. Kamas and Preston (2015) survey their students a couple of years after graduation to ask them to self-report their current earnings. As Reuben, Wiswall, and Zafar (2015), they find a strong positive relation between earnings, competitiveness, and confidence to the point that the gender gap in reported earnings disappears for women that are both competitive and confident. Compared to these studies, our study has two clear advantages. The first advantage is that our earnings data is not self-reported. It is given to us by business school, which corroborates the veracity of the data with the employers. This is an important difference since it is plausible that competitive and overconfident individuals are simply overstating their earnings. The second advantage is that, in addition to earnings, we also observe how participants sort themselves into different industries over a period of nine years. This allows us to establish whether competitiveness predicts labor market outcomes in the long run and to observe the stages in the participants' career where competitiveness plays an important role.

Two other studies investigate the relation between competitiveness and labor market outcomes. However, they do so in settings where men and women make similar choices, and therefore, they do not inform us on the relation between gender differences in competitiveness and gender gaps in the labor market. Zhang (2013) finds that competitiveness predicts whether middle school students in rural China take a highly demanding high school entrance exam. Berge et al. (2015) study small-scale 
entrepreneurs in Tanzania. They find that competitive entrepreneurs self-report investing more in their business and hiring more employees.

A last advantage of our study compared to the studies reviewed in this section is that we implemented a clever control treatment of the Niederle and Vesterlund (2007) design. Namely, we gave participants a second choice between tournament and piece-rate pay in a setting with the same monetary incentives and information conditions as their initial choice but without the need to perform under competitive conditions. Like Niederle and Vesterlund (2007), we find that women do not shy away from tournaments that do not involve competition. More importantly, we find a much weaker relation between earnings and choosing tournament pay in the absence of competition, which lends support to the interpretation of competitiveness as the driver of our results.

\section{Study design}

The data we use in this paper come from MBA graduates from of the 2008 cohort of University of Chicago Booth School of Business. More specifically, we use data from four sources: an experiment and survey, the admissions office of University of Chicago Booth School of Business, the career services office of the same school, and publicly available profiles from LinkedIn.

\subsection{Survey and experiment}

As part of a required core class, all the MBA students of the 2008 cohort completed a survey and participated in an experiment designed to measure several individual-specific characteristics. Both the survey and the experiment were conducted in the fall of 2006, during their first month in the business school. Participants completed the survey online before they took part in the experiment. The survey took approximately one hour to complete while the experiment lasted an hour and a half. A detailed description of the procedures used to conduct the survey and experiment are provided in the supplementary materials.

The survey includes questions on demographic characteristics as well as standard questionnaires of personality traits. In this paper, we concentrate on three variables that are potentially important 
determinants of gender differences in labor market outcomes. ${ }^{3}$ The first variable is the participants' score in a four-question version of the cognitive reflection test (CRT) proposed by Frederik (2005). High scores in the CRT are associated with high IQ and better decision-making skills in various domains (Frederik, 2005; Toplak, West, and Stanovich, 2011) such as expertise in the finance sector (Thoma et al., 2015). Moreover, as reported by Frederik (2005), on average, men score better than women. The second variable is the participants' score in the "reading the mind in the eyes" test of Baron-Cohen et al. (2001), which consists of correctly recognizing the emotions of various individuals by looking at pictures of their eyes. High scores in this test are associated with a higher ability to empathize, which is arguably an important skill in leadership positions (Goleman and Boyatzis, 2008). As reported by Baron-Cohen (2002), on average, women score better than men in this test. The third variable corresponds to the measure of self-efficacy proposed by Sherer et al. (1982). Self-efficacy has been found to be strongly associated with work and academic performance (Lent and Hackett, 1987; Stajkovic and Luthans, 1998) as well as career choice (Eccles, 1994). Women tend to report lower self-efficacy than men (Lent and Hackett, 1987; Eccles, 1994; Schwarzer et al., 1997). Lastly, we also include the participants' self-reported religiosity as part of their demographic characteristics, which were mostly obtained from the admissions office.

The experiment consisted of eight distinct parts. The instructions for each part were given before the start of the respective part and participants received no feedback concerning the outcome or behavior of others until the experiment had concluded. As compensation, participants received a $\$ 20$ show-up fee and their earnings in a randomly selected part. On average, participants earned \$99.

Next, we describe the five parts of the experiment that were designed to measure individual characteristics, ${ }^{4}$ more specifically: risk preferences, time preferences, willingness to trust and reciprocate, willingness to cooperate, and competitiveness. Given the focus of this paper, we first provide a brief description of the first four parts and subsequently a detailed description of the part

\footnotetext{
3 The precise wording of the survey questions is available in the supplementary materials. All other survey questions are available in Reuben, Sapienza, and Zingales (2008).

4 The three parts not used in this study correspond to an asset market game, a chocolate auction, and a lottery. These parts were included to keep the students engaged throughout the experiment. They are described in Reuben, Sapienza, and Zingales (2008).
} 
used to measure competitiveness. Detailed descriptions of the first four parts are available in the supplementary materials.

To measure risk preferences, we gave participants 15 choices between a lottery with an expected value of $\$ 100$ and certain amount that ranged from $\$ 50$ to $\$ 120$. As is common in the literature, we then use these choices to determine each participant's risk aversion coefficient assuming a CRRA utility function (see Holt and Laury. 2002). Similarly, to measure time preferences, we elicited individual discount rates by giving each participant 13 choices between receiving their experimental earnings immediately and receiving an amount that ranged from $0 \%$ more to $12 \%$ more two weeks later. We use these choices to calculate each participant's two-week discount rate. We measured trust and reciprocity by having participants play a variation of the well-known trust game (Berg, Dickhaut, and McCabe, 1995). We had participants play the game twice, once as the trustor and once as the trustee. We use the fraction of the $\$ 50$ endowment that participants send as trustors as a measure of their willingness to trust and the fraction of the amount received that they return as trustees (conditional on receiving $\$ 150$ ) as a measure of their willingness to reciprocate. Finally, we measure the participants' willingness to cooperate by having them play a linear public good game in groups of eight (Isaac, Walker, and Thomas, 1984). We use the participants' contribution decision (either $\$ 0$ or $\$ 50$ ) as a measure of their willingness to cooperate.

To measure competitiveness, we use a variation of the design used by Niederle and Vesterlund (2007). Participants first performed an adding task under both a tournament payment scheme and a piece-rate payment scheme. Subsequently, they performed the task once again under a payment scheme of their choice. They payment-scheme choice serves as the basis for their competitiveness.

The task consisted of computing sums of four two-digit numbers for 150 seconds. The two-digit numbers are randomly drawn from a uniform distribution with a support of 11 to 99 . Calculators were not allowed. After each answer, a new set of numbers appeared on the computer screen along with a message indicating whether their answer was correct or incorrect. Importantly, although participants knew what their own performance was, they did not receive any information about the performance or choices of others during the experiment.

Participants were informed that this part of the experiment consists of four periods, one of which will be randomly chosen to determine their earnings. They were also informed that they were 
randomly assigned to groups of four. Participants read the instructions for each period just before the start of the respective period. In the first two periods, participants performed the addition task once under a piece-rate payment scheme and once under a tournament payment scheme. With piecerate pay, participants earned $\$ 4$ for every correct answer. With tournament pay, participants earned \$16 for every correct answer if they had the highest number of correct answers in their group (ties were broken randomly) and earned $\$ 0$ otherwise. Half the participants performed the addition task first under piece-rate pay and then under tournament pay while the other half performed the tasks in the reverse order.

In the third period, participants were informed that they would perform the addition task once again and were asked to choose one of the two payment schemes to apply in that period. If they chose piece-rate, they earned $\$ 4$ per correct answer. If they chose tournament, they earned $\$ 16$ per correct answer if they had more correct answers than their other group members had when they performed the task under tournament pay in the first or second period. Competing against their group members' previous performance has the advantage that the participants' choice in the third period is not affected by their beliefs about the competitiveness of others. Moreover, it prevents participants from selecting piece-rate pay in order to avoid imposing a negative externality on others.

In the fourth period, participants did not perform the adding task. This period simply consisted of choosing whether they wished to be paid for their previous performance according to the piece-rate or tournament payment schemes. Specifically, for their performance under the uncompetitive payment scheme in the first or second period. Thus, the participants' choice in the fourth period resembled their choice in the third period except that participants who chose tournament pay did not perform under the stress (or thrill) one might experience in a competitive environment.

After the fourth period, we elicited the participants' beliefs concerning their relative performance by asking them to guess how they ranked within their group in each of the first three periods. Participants submitted ranks between $1^{\text {st }}$ and $4^{\text {th }}$ and received $\$ 2$ for each correct guess. ${ }^{5}$ The instructions given to the participants are provided in the supplementary materials.

\footnotetext{
${ }^{5}$ In case of a tie, participants were paid the $\$ 2$ if their guess corresponded to a rank they could have received when the tie was randomly resolved.
} 


\subsection{Administrative data}

The admissions office of the business school supplied us with various variables collected when the participants applied for admission to the school. These variables include demographic characteristics such as age, race, marital status, and whether participants are residents of the United States. It also includes the participants' GMAT percentile scores (broken down into the quantitative, verbal, and analytic components), their work experience (in months), and the name of the employer they worked for before they joined the MBA program. We used two-digit NAICS industry codes to classify each participant's pre-MBA employer into three broad industry categories: finance (two-digit NAICS code 52), professional services, which we refer to as "consulting" (two-digit NAICS code 54), and "other" (the remaining two-digit codes). Lastly, upon graduation, we also received from the school administration each participant's GPA in the MBA program.

\subsection{Job data}

The career services office of the business school provided us with information regarding the job participants accepted upon graduation. The information was initially reported by the participants but the career services office subsequently double-checked it with the respective employers to ensure its accuracy. The information included data on financial earnings, which includes salaries as well as yearly and one-time bonuses (e.g., sign-on and relocation bonuses). Based on this information we calculated the participants' total earnings in their first year after graduation. The information also included the employers' names, which we used to classify them into the three industry categories: finance, consulting, or other.

Also from the career services office, we received self-reported information from a survey completed by the participants. It included the following information: whether participants successfully negotiated their job offer, whether their job was obtained through the school's recruitment events or through personal contacts, and whether they obtained competing job offers and if so, the financial compensation of those offers.

Finally, we also obtained information regarding the recruitment process in the business school. To obtain a job, MBAs go through a two-step process. In the first year, MBA students obtain an internship in a firm in which they are potentially interested. In the second year, MBA students decide 
whether to stay at the firm for which they interned (if they are offered a job) or seek employment in another firm. Interviewing for internships and jobs occurs mostly within the school premises at various points throughout the MBA program. In other words, the school serves as a centralized twosided market for job candidates and employers. This gives us access to information about the demand and supply sides of the market. On the demand side, employers report to the school which participants they would like to interview. On the supply side, participants get an allocation of points from the school to subsequently bid for interviews with particular employers.

\subsection{LinkedIn data}

In September 2015, we followed up on the study's participants by looking for their profile in LinkedIn, a business-oriented social networking service where individuals list, among other things, their employment history. We used the participant's listed employer to classify them once again into the three industry categories.

\section{Descriptive statistics}

Although participation in some parts of the study was mandatory, participants had the option to opt out of the study by not consenting to the use of some or all of their data. Out of the 550 students in the cohort, 409 (74\%) consented to the analysis of the survey, experiment, administrative, and job placement data. Throughout the paper, we concentrate on these participants. However, it is important to understand whether this sample differs systematically from the rest of the cohort. For this reason, in the supplementary materials we conduct a thorough comparison between the 409 participants in the sample and 129 participants for whom we can analyze data sources other than their job placement data. 6 By and large, we do not find differences between these two populations. Crucially for this paper, neither the fraction of women nor the fraction of participants who chose tournament pay is significantly different $\left(\chi^{2}\right.$ tests, $\left.p>0.388\right) .^{7}$

\footnotetext{
${ }^{6}$ Of these 129 participants, we have compensation data for 62 participants. Of these participants, 26 did not consent to the use of their compensation data and 36 had job offers that were not reviewed by the school's career services office.

${ }^{7}$ It is also the case that neither the fraction of men nor the fraction of women who chose tournament pay significantly differ between the two populations ( $\chi^{2}$ tests, $p>0.704$ ). Using a threshold of $10 \%$ and adjusting $p$-values to account for multiple
} 


\section{Table 1 - Summary statistics by gender}

Note: Means and standard deviations for variables obtained from the experiment, survey, and the admissions office. There are 286 men and 123 women in the sample. The rightmost column displays $p$-values from tests of equality of distributions between men and women based on $t$-tests for ordinal variables and $\chi^{2}$ tests for categorical variables.

\begin{tabular}{lccccc}
\hline \hline & \multicolumn{2}{c}{ MEN } & \multicolumn{2}{c}{ WOMEN } \\
& mean & s.d. & mean & s.d. & $p$-value \\
\hline Experiment and survey & & & & & \\
Fraction choosing tournament pay & 0.601 & 0.490 & 0.333 & 0.473 & 0.000 \\
Probability of ranking 1st in tournament & 0.283 & 0.296 & 0.189 & 0.245 & 0.001 \\
Probability of ranking 1st in piece-rate & 0.289 & 0.303 & 0.174 & 0.229 & 0.000 \\
Expected rank in tournament & 2.136 & 0.925 & 2.545 & 0.926 & 0.000 \\
Risk aversion coefficient & 4.223 & 4.191 & 5.942 & 4.690 & 0.001 \\
Discount rate & 0.052 & 0.045 & 0.049 & 0.042 & 0.437 \\
Trust & 0.399 & 0.304 & 0.346 & 0.286 & 0.088 \\
Reciprocity & 0.366 & 0.218 & 0.356 & 0.168 & 0.623 \\
Cooperation & 0.322 & 0.468 & 0.350 & 0.479 & 0.582 \\
CRT & 2.710 & 1.269 & 1.805 & 1.259 & 0.000 \\
Empathizing & 0.738 & 0.101 & 0.764 & 0.091 & 0.012 \\
Self-efficacy & 4.157 & 0.825 & 4.016 & 0.830 & 0.116 \\
Fraction religious & 0.493 & 0.501 & 0.415 & 0.495 & 0.145 \\
\hline Administrative & & & & & \\
Age & 28.641 & 2.311 & 27.245 & 2.474 & 0.000 \\
Fraction non-white & 0.521 & 0.500 & 0.618 & 0.488 & 0.071 \\
GMAT Quantitative percentile & 84.070 & 11.099 & 76.885 & 14.990 & 0.000 \\
GMAT Verbal percentile & 88.458 & 11.321 & 86.992 & 11.720 & 0.244 \\
GMAT Analytic percentile & 72.396 & 21.537 & 70.743 & 22.308 & 0.505 \\
Fraction US residents & 0.766 & 0.424 & 0.772 & 0.421 & 0.884 \\
Fraction married & 0.297 & 0.458 & 0.163 & 0.371 & 0.004 \\
GPA & 3.362 & 0.336 & 3.246 & 0.346 & 0.003 \\
Pre-MBA work experience & 63.966 & 23.635 & 53.387 & 24.843 & 0.000 \\
Fraction with pre-MBA job in finance & 0.287 & 0.453 & 0.301 & 0.460 & 0.773 \\
Fraction with pre-MBA job in consulting & 0.301 & 0.459 & 0.252 & 0.436 & 0.318 \\
\hline \hline & & & & &
\end{tabular}

Next, we provide descriptive statistics for participants in our sample and evaluate whether there are gender differences in the experimental, survey, and administrative data. Table 2 presents the mean and standard deviation for variables derived from these data sources for both the 286 men and 123 women in the sample. For each variable, the table also displays $p$-values from tests of equality of 
distributions between men and women based on $t$-tests for ordinal variables and $\chi^{2}$ tests for categorical variables. ${ }^{8}$

As can be seen in the table, there are various differences between men and women. Compared to men, women are just over one year younger, have lower GMAT quantitative scores, are half as likely to be married, had almost one year less of work experience at the start of the MBA, and graduate with a lower GPA. In the experiment and survey, we replicate many of the gender differences reported in the literature. Namely, we find that, relative to men, women in our sample are more risk averse (Croson and Gneezy, 2009), have lower CRT scores (Frederik, 2005), and higher empathizing scores (Baron-Cohen, 2002). ${ }^{9}$ Also consistent with the mixed results in the literature, we do not find a significant difference between men and women in their willingness to cooperate, reciprocate, or trust (see Croson and Gneezy, 2009). Next, we focus on competitiveness and evaluate whether male MBAs are more competitive than female MBAs.

\section{Gender differences in competitiveness}

Consistent with the literature on competitiveness, we can see in Table 1 that $60.1 \%$ of men choose the tournament payment scheme compared to $33.3 \%$ of women. ${ }^{10}$ However, on its own, the higher incidence of men choosing tournament pay is not enough to conclude that men are more competitive. In particular, Table 1 also reveals that men in our sample outperform women in the adding tasks. ${ }^{11}$ For example, the average probability of being ranked first in a randomly selected group of four is

8 All tests in the paper are two-sided.

${ }_{9}$ Adjusting $p$-values with the Benjamini-Hochberg method to account for multiple comparisons does not affect these conclusions.

10 For example, a gender difference in the choice of tournament pay has been found in Niederle and Vesterlund (2007), Cason, Masters, and Sheremeta (2010), Healy and Pate (2011), Balafoutas and Sutter (2012), Reuben et al. (2012), and Niederle, Segal, and Vesterlund (2013), in addition to experiments that vary the design in important ways like Gneezy, Leonard, and List (2009), Dohmen and Falk (2011), Booth and Nolen (2012), Andersen et al. (2013), and Gupta, Poulsen, and Villeval (2013).

11 Most papers using the design of Niederle and Vesterlund (2007) find no gender difference in performance. However, the higher performance of men in our sample is in line with men having higher average quantitative GMAT scores. That being said, there is considerable overlap in the two distributions. For instance, the median woman beats $45.3 \%$ of all men. We do not find that either men or women perform differently depending on the type of payment scheme $(t$-tests, $p>0.280)$, but they do improve from the first to the second period ( $t$-tests, $p \leq 0.001$ ). 
Table 2 - Determinants of choosing tournament pay

Note: Regressions of the decision to choose tournament pay. OLS estimates and standard errors in parenthesis. ${ }^{* * *},{ }^{* *}$, and ${ }^{*}$ indicate statistical significance at $0.01,0.05$, and 0.10 .

\begin{tabular}{lcccc}
\hline \hline & I & II & III & IV \\
\hline Woman & $-0.268^{* * *}$ & $-0.199^{* * *}$ & $-0.133^{* * *}$ & $-0.108^{* *}$ \\
& $(0.052)$ & $(0.050)$ & $(0.049)$ & $(0.054)$ \\
Probability of ranking 1, ${ }^{\text {st }}$ in tournament & & $0.182^{* * *}$ & $0.098^{* * *}$ & $0.090^{* * *}$ \\
& & $(0.025)$ & $(0.029)$ & $(0.030)$ \\
Probability of ranking 1 15 in tournament - piece-rate & & $-0.097^{* * *}$ & $-0.0121^{* * *}$ & $-0.107^{* * *}$ \\
& & $(0.025)$ & $(0.024)$ & $(0.025)$ \\
Expected rank in tournament & & & $-0.150^{* * *}$ & $-0.129^{* * *}$ \\
& & & $(0.028)$ & $(0.029)$ \\
Risk aversion coefficient & & & $-0.070^{* * *}$ & $-0.065^{* * *}$ \\
& & & $(0.022)$ & $(0.023)$ \\
\hline Controls & No & No & No & Yes \\
\hline Obs. & 409 & 409 & 409 & 409 \\
$\mathrm{R}^{2}$ & 0.061 & 0.171 & 0.245 & 0.292 \\
\hline \hline
\end{tabular}

around $28 \%$ for men and $18 \%$ for women (the difference is statistically significant under both tournament and piece-rate pay). ${ }^{12}$ Consistent with their higher performance, on average, men expect to be better ranked than women (2.136 vs. 2.545). ${ }^{13}$ These differences, combined with the fact that women are more risk averse, could explain why men choose tournament pay more often than women do.

Are male MBAs more competitive than female MBAs after controlling for their ability, beliefs, and risk preferences? To answer this question we follow Niederle and Vesterlund (2007) and Buser, Niederle, and Oosterbeek (2014) and run a series of regressions with the participants' choice of

\footnotetext{
12 On average per period, men got 7.549 correct answers while women get 6.569 correct answers. However, throughout the paper, we concentrate on the probability of ranking first because it is the more relevant statistic for the participants' choice between tournament and piece-rate pay. We calculate these probabilities through simulation. We use the participants' number of correct answers in each of the first two periods and randomly assign participants to groups of four 10,000 times. Like in the experiment, in each period, participants were matched with those under the same payment scheme. We then calculate the fraction of times participants are ranked first in their group (ties are broken randomly). All results are robust to using the number of correct answers instead.

13 We concentrate on the participants' expected rank when they perform under tournament pay since this expectation is arguably more relevant for their payment scheme choice. All results are robust to using their expected rank under piecerate pay instead.
} 
tournament pay as the dependent variable. To facilitate the interpretation of the coefficients, we standardize the ordinal independent variables to have a mean of zero and a standard deviation of one. The results are reported in Table 2. In column I, the only independent variable is the participants' gender. Without any controls, the gender gap in tournament pay equals $26.8 \%$. In column II, we control for the participants' ability by including their probability of ranking first in the first two periods (included as their probability of ranking first under tournament pay and the difference between this probability and their probability of ranking first under piece-rate pay). Controlling for ability, narrows the gender gap in tournament pay by 6.9 percentage points to $19.9 \%$. In column III, we further control for the participants' beliefs (their expected rank under tournament pay) and risk preferences (their risk aversion coefficient). As we can see, ability, beliefs, and risk preferences are all significant determinants of the decision to compete. However, controlling for these variables still leaves a statistically significant gender gap in tournament pay of $13.3 \%$.

In summary, MBAs in our sample display a gender gap in choosing tournament pay similar to those reported in other populations (see Niederle and Vesterlund, 2011). Controlling for their ability, beliefs, and risk preferences accounts for roughly half of the gender difference in tournament pay. As Niederle and Vesterlund (2007), we interpret the remaining gender gap as being driven by gender differences in competitiveness.

A question that naturally arises is whether competitiveness describes variation in individual characteristics that is not captured by other observables. To answer this question, we run one more regression to which we add all the remaining variables in Table 1. As we can see in column IV, the inclusion of all these control variables has only a small effect on the magnitude of the gender gap in tournament pay: it shrinks by 2.5 percentage points to $10.8 \%$. In addition, we cannot reject the null hypothesis that the additional control variables are jointly significant ( $p=0.207)$. This is compelling evidence that competitiveness captures individual variation that would otherwise remain unobserved. 


\section{A. Means and $95 \%$ confidence intervals}

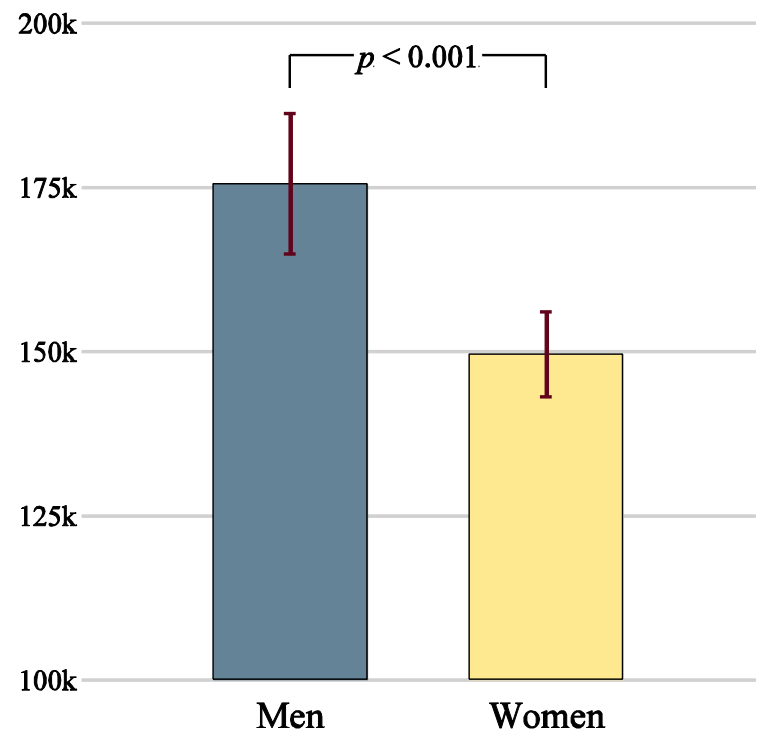

\section{B. Cumulative distribution}

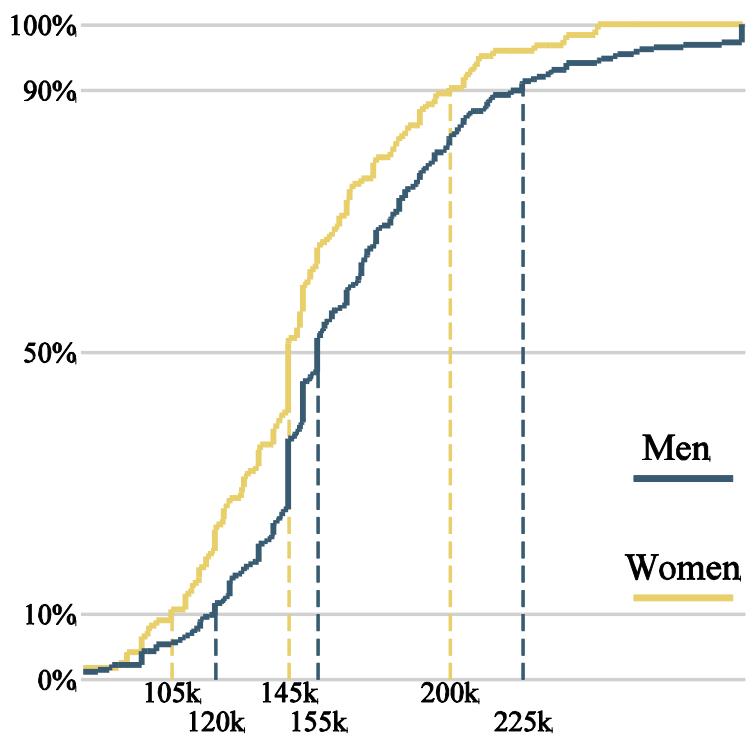

Figure 1 - Total yearly earnings in the first job after graduation by gender

\section{Gender differences in earnings}

In this section, we analyze the participants' total earnings in their first year after graduation. ${ }^{14} \mathrm{We}$ focus on gender differences in earnings, the relationship between earnings and competitiveness, and the extent to which gender differences in earnings are explained by the observed gender differences in competitiveness.

Figure $1 \mathrm{~A}$ shows the mean earnings of men and women. On average, male MBAs earned $\$ 175 \mathrm{k}$ in their first year after graduation whereas females MBAs earned $\$ 149 \mathrm{k}$. A $t$-test indicates that the gender difference in means is statistically significant $(p<0.001)$. Figure $1 \mathrm{~B}$ depicts the cumulative distributions of first-year earnings. We can see that the difference between men and women appears at all income levels, albeit it is larger for the top earners: at the $10^{\text {th }}$ percentile men outearn women by $\$ 15 \mathrm{k}$ while at the $90^{\text {th }}$ percentile this difference has grown to $\$ 25 \mathrm{k}$.

\footnotetext{
${ }^{14}$ As is common in the literature, to prevent a few outliers from unduly affecting our results, we winsorized the participants' earnings at the $1^{\text {st }}$ and $99^{\text {th }}$ percentiles (at $\$ 75 \mathrm{k}$ and $\$ 750 \mathrm{k}$ respectively). In the supplementary materials, we redo the regressions presented in this section with the non-winsorized values. All the regression results hold and in some cases become stronger with the non-winsorized values.
} 


\section{A. Means and $95 \%$ confidence intervals}

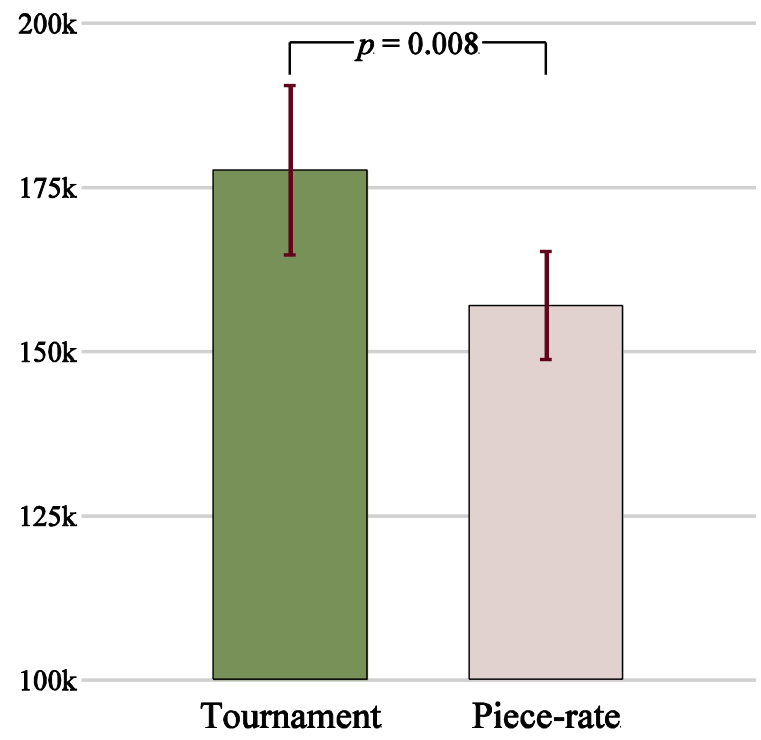

\section{B. Cumulative distribution}

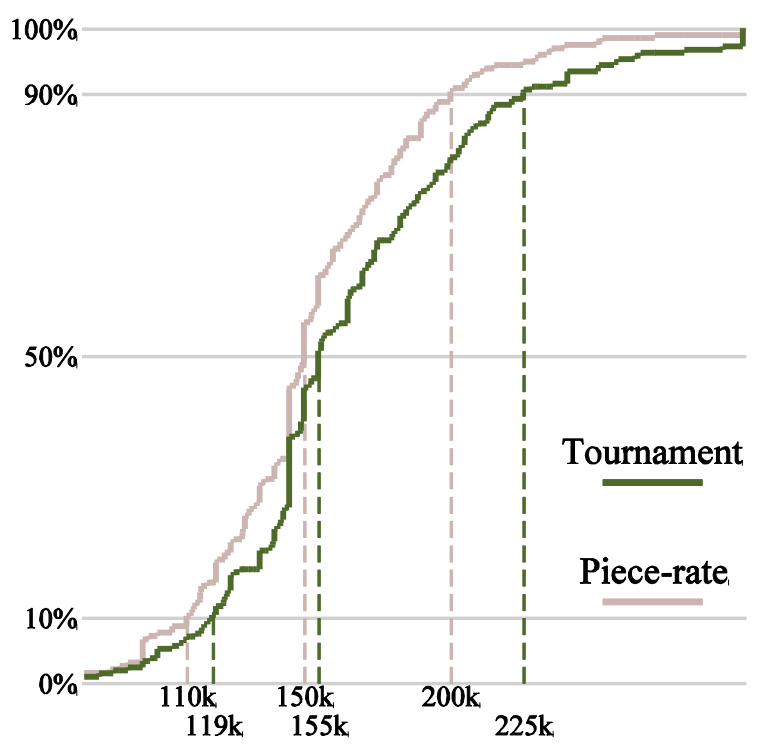

Figure 2 - Total yearly earnings in the first job after graduation by payment scheme choice

\subsection{Competitiveness and the gender gap}

As seen in Figure 2A, choosing tournament pay in a laboratory experiment at the beginning of their MBA is associated with higher earnings two years later in the participants' first job. On average, participants who chose tournament pay ended up earning $\$ 21 \mathrm{k}$ more than participants who chose piece-rate pay ( $t$-test, $p=0.008)$. As with gender, the difference in earnings is larger for the top earners (see Figure 2B).

Does this difference in competitiveness persist once we control for other determinants of choosing tournament pay? To answer this question, we run a series of linear regressions with the log of the participants' first-year earnings as the dependent variable. In all specifications, we control for the other determinants of choosing tournament pay (i.e., the variables in column III of Table 2) so that we capture the effect of competitiveness when we include tournament pay as an independent variable. The coefficients for the two variables of interest, gender and competitiveness, are presented in Table 3. The coefficients for all other independent variables are available in the supplementary materials.

The regression in column I includes gender as an independent variable (woman). The estimated coefficient simply confirms that women earn significantly less than men do (12.2 log points less). In column II, we add a dummy variable indicating whether participants chose tournament pay over 
piece-rate pay in the experiment (competitive). We are interested in two things: the size and significance of the competitive coefficient, and the change it produces on the gender coefficient, which can be interpreted as the part of the gender difference in earnings that is accounted for by the gender difference in competitiveness. We find that competitive participants earned significantly more than uncompetitive participants. Specifically, they earned 9.1 log points more, which is around $\$ 15 \mathrm{k}$. A large effect, comparable in size to the effect of gender..$^{15}$ In addition, including the tournament pay variable significantly reduces the gender gap in earnings by $9.9 \%$ (the gender coefficient changes from -0.122 to $-0.110, p=0.012$ bootstrapped as in Buser, Niederle, and Oosterbeek, 2014), which in dollar terms is approximately $\$ 2 \mathrm{k}$.

How important is the role of competitiveness in accounting for the gender gap in earnings? One way to answer this question is to compare the impact of competitiveness on the gender coefficient to the impact of other control variables on the same coefficient. This can be done by looking at column III, which includes all the variables in Table 1 except for tournament pay. Including these control variables noticeability reduces the gender gap by $20.7 \%$ (the gender coefficient changes from- 0.122 to -0.097). This result puts the effect of competitiveness in perspective. Namely, the single experimental measure of competitiveness explains around half as much of the gender gap in earnings as a rich set of variables that include demographic characteristics, academic performance, and experimental and survey measures of important psychological attributes. ${ }^{16}$

Lastly, we evaluate the effects of competitiveness whilst controlling for the other variables in Table 1. The effects can be seen in column IV, which includes both the tournament pay dummy and the control variables from Table 1. By comparing column II and column IV, we can see that the competitive coefficient is unaffected by the inclusion of all these control variables and remains a sizable 8.8 log points. By comparing column III and column IV, we can see that the inclusion of tournament pay further reduces the gender gap by roughly the same amount as before (the gender

\footnotetext{
15 The effect of competitiveness is similar for both genders. The interaction of being competitive and gender is not statistically significant irrespective of whether we include the additional controls or not $(p>0.420)$.

16 An alternative comparison is to look at the impact on the gender coefficient of including each variable in Table 1 separately. If we do this, the variables that significantly decrease the gender coefficient are the participants' CRT score, GMAT quantitative percentile, marital status, and GPA. The effects of these variables are comparable in size, competitiveness being the second-strongest effect after marital status.
} 


\section{Table 3 - Determinants of earnings}

Note: Regressions of the MBAs' log of total earnings in their first year after graduation. All regressions include the variables in column III of Table 2 as determinants of choosing tournament pay that are unrelated to competitiveness. Controls refers to all the remaining variables in Table

1. The change in coefficient for woman refers to the percentage change from columns I to II or III to IV; bootstrapped $p$-values for this change are provided in the next row. OLS estimates and standard errors in parenthesis. ${ }^{* * *}{ }^{* *}$, and ${ }^{*}$ indicate statistical significance at $0.01,0.05$, and 0.10 .

\begin{tabular}{lcccc}
\hline \hline & I & II & III & IV \\
\hline Woman & $-0.122^{* * *}$ & $-0.110^{* * *}$ & $-0.097^{* * *}$ & $-0.087^{* *}$ \\
& $(0.035)$ & $(0.035)$ & $(0.038)$ & $(0.038)$ \\
Competitive & & $0.091^{* * *}$ & & $0.088^{* *}$ \\
& & $(0.035)$ & \multicolumn{2}{c}{$0.035)$} \\
\hline Controls & No & No & Yes & Yes \\
\hline Change in coefficient for woman & \multicolumn{2}{c}{$9.9 \%$} & & \multicolumn{2}{c}{$9.8 \%$} \\
Bootstrap $p$-value & \multicolumn{2}{c}{0.012} & \multicolumn{2}{c}{0.040} \\
\hline Obs. & 409 & 409 & 409 & 409 \\
$\mathrm{R}^{2}$ & 0.032 & 0.048 & 0.122 & 0.136 \\
\hline \hline
\end{tabular}

coefficient changes from -0.097 to $-0.087, p=0.040$ ). In other words and consistent the little explanatory power of the control variables on tournament pay (see Table 2), the experimental measure of competitiveness accounts for an important part of the gender gap in earnings that is not captured by standard explanatory variables.

\subsection{Additional analysis}

In the supplementary materials, we provide additional results and robustness checks concerning the association between competitiveness and earnings. In particular, we present evidence that supports the interpretation of the association between earnings and choosing tournament pay as an association between earnings and competitiveness. In addition, we analyze the effect of competing job offers on the participants' final earnings. We briefly discuss these two analyzes below. For interested readers, in the supplementary materials, we also consider the role of negotiation and social contacts as potential drivers of gender differences in earnings. Moreover, we also demonstrate that the results of this section are robust to the following alternative specifications: (i) the exclusion of first-year bonuses (e.g., relocation, signing, and year-end bonuses) from the participants' earnings, (ii) the use of non-winsorized earnings, and (iii) the use of earnings in dollars instead of logs. 


\section{Competitiveness and tournament pay}

A clever feature of the experimental design of Niederle and Vesterlund (2007) is that participants make two choices between tournament and piece-rate pay. In one case, participants subsequently perform under the chosen payment scheme while in the other case the payment scheme is simply applied to their past performance (see section 3.1). We will refer to the choice of tournament pay in the latter case as "uncompetitive tournament pay." Because it does not include performing in a competitive environment, Niederle and Vesterlund (2007) argue that the choice between price-rate and uncompetitive tournament pay is unaffected by the participants' attitudes towards competition. If this is the case and the association between earnings and tournament pay is driven by competitiveness, then we should observe a weaker relation between earnings and uncompetitive tournament pay. ${ }^{17}$

To evaluate whether choosing uncompetitive tournament pay is associated with earnings, we run regressions like the ones reported in columns II and IV of Table 3. In some regressions, we simply substitute tournament pay with uncompetitive tournament pay. We find that the coefficients for uncompetitive tournament pay are positive, but they are not statistically significant and they are half as large as the comparable coefficient in Table 3. In addition, the change in the gender coefficient due to the inclusion of uncompetitive tournament pay is much smaller and is not statistically significant. In other regressions, we include both tournament pay and uncompetitive tournament pay. We find that the coefficient for tournament pay is both economically and statistically significant whereas the coefficient for uncompetitive tournament pay is close to zero and far from statistical significance. These results provide compelling evidence that the association between tournament pay and earnings is indeed driven by the participants' attitudes towards competition and is not related to the choice of a tournament payment scheme per se.

\footnotetext{
17 Like with tournament pay, men chose uncompetitive tournament pay significantly more often than women (47.2\% of men vs. $25.2 \%$ of women, $p<0.001$ with a $\chi^{2}$ test). However, unlike for tournament pay, this gender difference is no longer statistically significant once we control for the participants' ability, beliefs, risk preferences, demographic characteristics, and psychological traits $(p=0.240)$.
} 


\section{Competing job offers}

Competing job offers are a potential contributing factor to earnings differences. As mentioned in section 3.3, the career services office asks participants to report whether they had competing job offers and their respective compensation. On average, participants receive 0.416 competing offers with the average competing offer paying $\$ 168 \mathrm{k}$ in total earnings. Importantly, obtaining a competing job offer is strongly associated with significantly higher earnings. Regressing total earnings on a dummy variable indicating whether a participant has at least one competing job offer and the compensation of the best competing offer (as well as the controls from Table 1), reveals that a participant with a competing job offer of $\$ 168 \mathrm{k}$ earns $\$ 16 \mathrm{k}$ more than a participant with the same characteristics but without a competing offer.

Are competitive participants more likely to obtain a competing offer and if so, do they receive offers with higher compensation? The answer to the first part of this question is no. On average, participants who chose tournament pay obtained 0.394 competing offers while those who chose piece-rate pay obtained 0.439 competing offers. ${ }^{18}$ By contrast, the answer to the second part of the question is yes. Among participants who obtained at least one competing job offer, those who chose tournament pay obtained competing offers that paid, on average, $\$ 28 \mathrm{k}$ more than the competing offers of those who chose piece-rate pay. A regression of the log of earnings of competing job offers on tournament pay and the control variables in column III of Table 2 confirms that the competing job offers obtained by competitive participants are significantly better paid ( $p=0.041)$.

Consistent with the effect of competitiveness on earnings being channeled through competing job offers, the inclusion of these variables in the regressions of Table 3 weakens the coefficient of competitiveness from 8.8 to 6.3 log points. In other words, competitive participants are able to obtain job offers with higher earnings both from the firm they end up working at and from competing firms. It is not clear from our data, however, whether competitive participants use their better-paid offers

\footnotetext{
${ }_{18}$ Moreover, regressing the number of competing offers on tournament pay and the control variables in column III of Table 2 results in a small and non-significant coefficient.
} 
to improve their final earnings or whether they obtain higher earnings from different firms independently. ${ }^{19}$

\section{Gender differences in selection into industries}

In the previous section, we found a strong association between the MBAs' attitudes towards competition and their earnings at graduation. In this section, we investigate whether competitiveness has a long-term effect on earnings. In a previous study with the same population, Bertrand, Goldin, and Katz (2010) show that the industry MBAs work in is a strong determinant of their earnings over a period of ten years. Moreover, they also demonstrate that industry selection is an important contributing factor to the gender gap in earnings. Hence, by looking at the relations between competitiveness and the participants' industry over time, we gain insights about the long-term effect of competitiveness on earnings and the gender gap.

As mentioned in section 3, we used two-digit NAICS industry codes to classify the participants' employers into three broad categories: finance, consulting, and other industries. From the information we obtained from the business school, we know the participants' employers when they applied to their MBA and at graduation. From LinkedIn, we know their current employer. As one would expect, not all the study's participants have an updated profile in LinkedIn. Fortunately, we were able to get employment information from 390 participants ( $95 \%$ of the sample).

Figure 3A shows the fraction of men and women in each of the three industry categories. There is a significant gender difference in the participants' industry $\left(\chi^{2}\right.$ tests, $\left.p<0.006\right)$. At graduation, a higher fraction of men work in finance while a higher fraction of women work in consulting and other industries. This gender difference persists over time even though both men and woman shift towards other industries as their career progresses. From the point of view of predicting future earnings, the

\footnotetext{
19 The inclusion of competing offers also reduces the magnitude of the gender coefficient. Interestingly, the effect of competing job offers differs by gender. The increase in the earnings of men due to a competing job offer is about twice as large as the increase in the earnings of women. These findings are consistent with the literature on gender differences in the willingness and ability to bargain for higher wages (e.g., Babcock and Laschever, 2003; Small et al., 2007; Exley, Niederle, and Vesterlund, 2015; Leibbrandt and List, 2015). That being said, with our data we cannot test whether the association between earnings and competing job offers is driven by an improved bargaining position or by qualities of the job candidates that are not captured by the other control variables.
} 


\section{A. Distributions by gender}

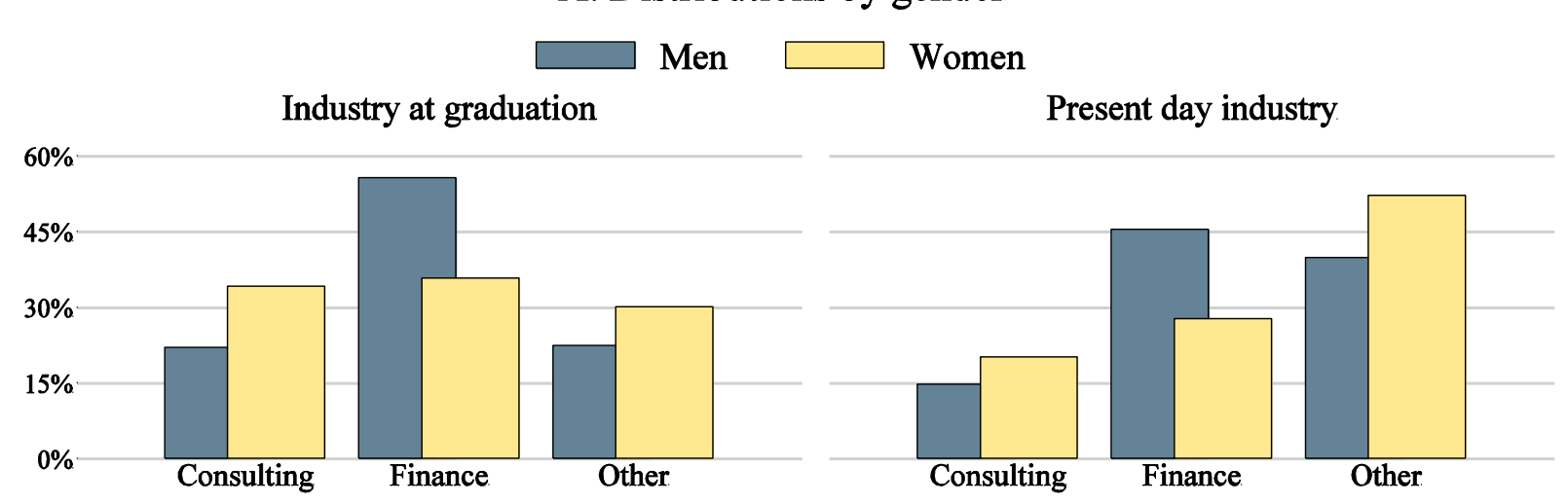

B. Distributions by payment scheme choice

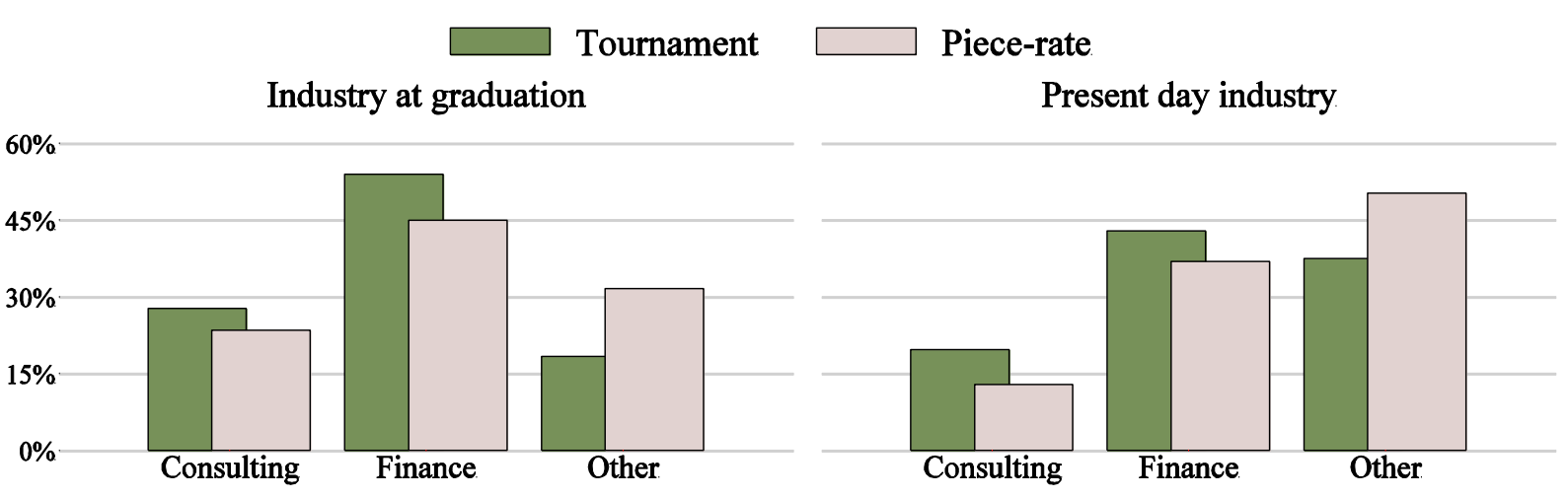

Figure 3 - Fraction of participants in the three industry categories

Note: The present day occurred seven years after graduation.

more important gender difference is the higher fraction of women working for employers in other industries, which tend to have lower earnings than those in finance and consulting (Bertrand, Goldin, and Katz, 2010). For example, in our sample, the average earnings at graduation was $\$ 177 \mathrm{k}$ in finance, $\$ 167 \mathrm{k}$ in consulting, and $\$ 151 \mathrm{k}$ in other industries. ${ }^{20}$ Bertrand, Goldin, and Katz (2010) find that these industry differences grow over time.

\subsection{Competitiveness and selection into industries}

We can see from Figure 3B that participants who chose tournament pay in the experiment self-select into different industries than participants who chose piece-rate pay $\left(\chi^{2}\right.$ tests, $\left.p<0.026\right)$. In particular,

\footnotetext{
20 Using $t$-tests, we find a significant difference in earnings between other industries and finance $(p=0.010)$ as well as other industries and consulting ( $p=0.046)$ but not between finance and consulting $(p=0.202)$.
} 


\section{Table 4 - Marginal effect of gender, competitiveness, and risk aversion, on the fraction of participants working in each industry}

Note: Marginal effects of gender, competitiveness, and risk aversion on the fraction of participants working in each industry at graduation and in the present day (seven years after graduation). Marginal effects are estimated from multinomial probit regressions of the participants' industry. All regressions include the variables in column III of Table 2 as determinants of choosing tournament pay that are unrelated to competitiveness. Controls refers to all the remaining variables in Table 1 . Standard errors are in parenthesis. ${ }^{* * *},{ }^{* *}$, and ${ }^{*}$ indicate statistical significance at $0.01,0.05$, and 0.10 .

\begin{tabular}{lcccccc}
\hline \hline & \multicolumn{3}{c}{ INDUSTRY AT GRADUATION } & \multicolumn{3}{c}{ PRESENT DAY INDUSTRY } \\
& Consulting & Finance & Other & Consulting & Finance & Other \\
\hline Woman & $0.155^{* * *}$ & $-0.241^{* * *}$ & 0.085 & $0.102^{* *}$ & $-0.214^{* * *}$ & $0.113^{*}$ \\
& $(0.056)$ & $(0.060)$ & $(0.062)$ & $(0.046)$ & $(0.062)$ & $(0.068)$ \\
Competitive & 0.071 & 0.043 & $-0.115^{* *}$ & $0.076^{* *}$ & -0.006 & -0.070 \\
& $(0.047)$ & $(0.062)$ & $(0.051)$ & $(0.035)$ & $(0.066)$ & $(0.063)$ \\
Risk aversion coefficient & $0.047^{* *}$ & $-0.073^{* * *}$ & 0.026 & 0.021 & -0.044 & 0.023 \\
& $(0.020)$ & $(0.028)$ & $(0.024)$ & $(0.013)$ & $(0.029)$ & $(0.029)$ \\
\hline Controls & Yes & Yes & Yes & Yes & Yes & Yes \\
\hline Obs. & & 409 & & & 390 & \\
$\chi^{2}$ & & 111.020 & & & 104.274 & \\
\hline \hline
\end{tabular}

both at graduation and in the present day, participants who chose tournament pay are more likely to work in consulting and finance and are less likely to work in other industries.

To test whether these differences endure once we control for other variables, we run a multinomial probit regression with the participants' industry as the dependent variable. As independent variables, we include gender (woman), a dummy variable indicating whether participants chose tournament pay over piece-rate pay (competitive), other determinants of choosing tournament pay (see column III of Table 2), and all the remaining control variables from Table 1, which include the industry of the participants' employer before they began their MBA. ${ }^{21}$ We run a regression for the participants' industry at graduation and another one for their present day industry. The results for gender and competitive are reported Table 4 as conditional marginal effects for each industry category. We also report the marginal effects of the participants' risk preferences since they are often cited as one of the important factors explaining gender differences in career choice (see Cramer, et al., 2002; Hartog et al., 2002; Saks and Shore, 2005; Zafar, 2013). The marginal effects for the other independent variables are available in the supplementary materials.

\footnotetext{
${ }^{21}$ As in previous regressions, we standardized all ordinal variables to facilitate the interpretation of the results.
} 
We find that competiveness is a significant predictor of the participants' industry. At graduation, a competitive participant is $7.1 \%$ more likely to work in consulting, $4.3 \%$ more likely to work in finance, and $11.5 \%$ less likely to work in another industry. Risk aversion also has a noticeable effect. A one standard deviation increase in risk aversion decreases the likelihood of working in finance by $7.3 \%$ and increases the likelihood of working in consulting by $4.7 \%$ and other industries by $2.6 \%$. We observe the same pattern for the participants' industry in the present day, although, the effect is somewhat weaker for both variables. ${ }^{22}$ These findings suggest that competitiveness has an important long-run effect on earnings since competitive individuals are less frequent in lower-paying industries. By contrast, the effect of risk aversion is more ambiguous since it predominantly predicts a shift between finance to consulting. ${ }^{23}$ Lastly, it is worth noting that, even after controlling for competitiveness, risk aversion, and the other individual characteristics in Table 1, gender is still a very strong predictor of the participants' industry.

Next, we complement the above analysis by looking in more detail at how participants change the industry they work in from graduation to the present day. In particular, we investigate the effect of gender and competitiveness on the notable increase in the number of people working in other industries (see Figure 3). In Table 5, we can observe the pattern of how participants transition between industries depending on gender (above) and the participants' choice between tournament and piece-rate pay (below). Overall, only around $12 \%$ of participants who work in other industries at graduation subsequently transition to finance or consulting. By contrast, around $30 \%$ of those who work in finance and 55\% of those who work in consulting transition to another industry. In all cases, conditional on changing industries, the vast majority of transitions occur towards other industries.

\footnotetext{
22 Doing pairwise tests gives the following results. For competitiveness: the difference between consulting and other industries is significant in both regressions $(p<0.024)$; the difference between finance and other industries is weakly significant at graduation ( $p=0.064$ ) but not in the present day ( $p=0.584)$; and the difference between consulting and finance is not significant at graduation $(p=0.456)$ and is weakly significant in the present day $(p=0.095)$. For risk aversion: the difference between consulting and other industries is not significant in either regression $(p>0.303)$; the difference between finance and other industries is weakly significant at graduation $(p=0.065)$ but not in the present day $(p=0.236)$; and the difference between consulting and finance is significant at graduation $(p=0.006)$ and weakly significant in the present day $(p=0.055)$.

23 The coefficient for risk aversion in the regressions of the participants' earnings is negative, but it is small in magnitude and far from being statistically significant ( $p=0.934$ in the specification of column IV in Table 3).
} 
Table 5 - Fraction transitioning from each industry at graduation to each present day industry

Note: Each cell contains the fraction of participants who worked in industry $k$ at graduation and transitioned to work in industry $l$ by the present day. Fractions are calculated for each gender (above) and depending on the participants' choice between tournament and piece-rate pay (below). The present day occurred seven years after graduation.

\begin{tabular}{|c|c|c|c|c|c|c|c|}
\hline & & \multicolumn{6}{|c|}{ Present day industry } \\
\hline & & & MEN & & & WOMEN & \\
\hline & & Consulting & Finance & Other & Consulting & Finance & Other \\
\hline \multirow{5}{*}{$\begin{array}{l}\text { Industry at } \\
\text { graduation }\end{array}$} & Consulting & 0.435 & 0.145 & 0.419 & 0.429 & 0.143 & 0.429 \\
\hline & Finance & 0.061 & 0.743 & 0.196 & 0.095 & 0.619 & 0.286 \\
\hline & Other & 0.066 & 0.066 & 0.869 & 0.057 & 0.029 & 0.914 \\
\hline & & \multicolumn{3}{|c|}{ TOURNAMENT } & \multicolumn{3}{|c|}{ PIECE-RATE } \\
\hline & & Consulting & Finance & Other & Consulting & Finance & Other \\
\hline \multirow{3}{*}{$\begin{array}{l}\text { Industry at } \\
\text { graduation }\end{array}$} & Consulting & 0.458 & 0.203 & 0.339 & 0.400 & 0.067 & 0.533 \\
\hline & Finance & 0.093 & 0.682 & 0.224 & 0.036 & 0.759 & 0.205 \\
\hline & Other & 0.081 & 0.054 & 0.865 & 0.051 & 0.051 & 0.898 \\
\hline
\end{tabular}

That being said, there are interesting differences between men and woman as well as between competitive and uncompetitive individuals. We test whether these differences in industry transitions are statistically significant by running a multinomial probit regression with the participants' industry in the present day as the independent variable. As independent variables, we use dummy variables to indicate the participants' industry at graduation, which we interact with the participants' gender, choice of tournament pay, and risk aversion coefficient. In addition, we include all the control variables in Table 1.

We find two interesting statistically significant effects. First, women who start their careers in finance are significantly more likely to move to other industries than men $37.1 \%$ of women who work in finance switch compared to $25.7 \%$ of men, $p=0.025)$. Second, individuals who started their career in consulting are significantly more likely to transition to finance and less likely to transition to other industries if they chose tournament pay compared to individuals who chose piece-rate pay $(p=0.016) \cdot{ }^{24}$

In summary, we find that the measures of competitiveness and risk aversion are good predictors of the industry participants' work in after graduation. Competitive individuals shy away from lower-

\footnotetext{
24 An additional significant effect exists: individuals who started their career in finance are significantly more likely to transition to consulting if they chose tournament pay compared to individuals who chose piece-rate pay $(p=0.025)$. Risk aversion had no significant effect on industry transitions.
} 
A. Distributions by gender
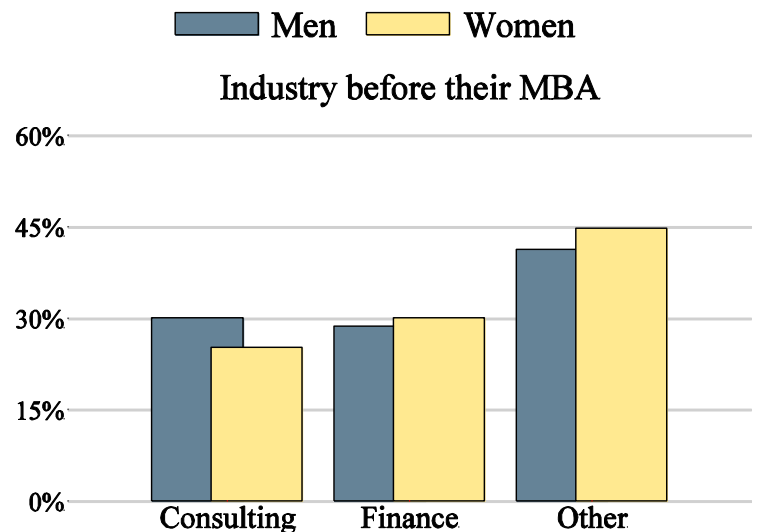

B. Distributions by payment scheme choice

$\square$ Tournament $\square$ Piece-rate

Industry before their MBA

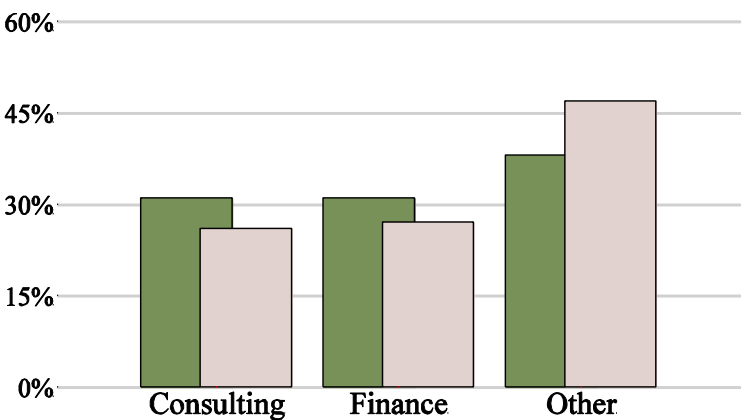

Figure 4 - Fraction of participants in the three industry categories before starting their MBA

paying jobs in other industries in favor of jobs in consulting and to a lesser extent finance. Risk averse individuals avoid job in finance in favor of jobs in consulting. The effect of competitiveness persists seven years later in spite of a noticeable shift towards jobs in other industries because competitive individuals from consulting are less likely to move to other industries and more likely to move into finance..$^{25}$

\subsection{The emergence of the gender and competitiveness gaps in industry selection}

In this last section, we use the data we collected from the job-matching process to study the observed gender differences in selection into industries. Based on their jobs before the start of their MBA, Figure 4 shows the fraction of participants in each of the three industry categories depending on their gender (A) and payment scheme choice in the experiment (B). Even though we observe some of the same patterns as in the distribution of industries after graduation (e.g., women and individuals who chose piece-rate pay are more frequent in other industries, see Figure 3), it is clear that these patterns a much less pronounced before participants started their MBA. In fact, neither gender nor choosing tournament pay are significant predictors of the participants' industry before they obtained an MBA

\footnotetext{
25 In addition to industry, Bertrand, Goldin, and Katz (2010) find that the fraction of finance classes taken during their MBA is a strong predictor of earnings in the long run. Interestingly, competitiveness is positively and significantly associated with the fraction of finance classes taken by our participants. In particular, a regression of the fraction of finance classes on the participants' gender, competitiveness, the control variables from Table 2, and their industry at graduation results in a negative coefficient for gender $(p<0.001)$, a positive one for competitiveness $(p=0.026)$, and a nonsignificant coefficient for risk aversion $(p=0.649)$.
} 
degree ( $\chi^{2}$ tests, $p=0.602$ and $p=0.188$ respectively). ${ }^{26}$ The advantage of our data is that we can observe the stages in the MBAs' job market in which gender and competitiveness emerge as significant determinants of industry selection.

Before they got a job in the second year of the MBA, participants obtained and completed a summer internship (see section 3.3). Interviews for internships are arranged through the business school's job market. On the demand side, employers signal their interest to participants by inviting them to an interview. On the supply side, participants signal their interest to employers by biding for interviews. After observing the bids, employers decide on a final pool of candidates to interview. Subsequently, employers make offers and participants decide which internship to accept. On average, participants received 6.377 invitations, sent a bid to 7.027 firms, and took part in 8.242 interviews.

After the summer internships conclude, employers decide whether to extend a job offer to their interns, which then decide whether to accept the offer or look for another job. Overall, $61.6 \%$ of our participants received an offer from their internship firm and $49.6 \%$ accepted it. For participants who did not continue with their internship firm, the entire process repeats itself: firms extend invitations, participants send bids, a new round of interviews ensues, and final offers are made and accepted. On average, the 206 participants who did not continue with their internship firm received 5.083 invitations, sent a bid to 4.684 firms, and took part in 6.903 interviews. ${ }^{27}$

Are there differences in the aggregate job-market statistics depending on the participants' gender and competiveness? In the supplementary materials, we show that, for both internships and jobs, male and female participants received a similar number of invitations, sent bids to a similar number of firms, and took part in a similar number of interviews. They are also equally likely to receive or accept an offer from their internship firm. Likewise, we do not observe important differences between participants who chose tournament pay and those who chose piece-rate pay. These results

\footnotetext{
${ }^{26}$ If we run a multinomial probit regression to estimate the effect of gender and competitiveness controlling for other variables (like the regressions in Table 4), we confirm that neither gender nor competitiveness are significant predictors of the participants' industry before their MBA (pairwise tests, $p>0.158$ and $p>0.422$ respectively).

27 Participants who received an offer from their internship firm could still take part in the job market if they postponed their acceptance. Some of them do so in a limited way. On average, the 203 participants who continued with their internship firm received 1.049 invitations, sent a bid to 0.734 firms, and took part in 1.241 interviews.
} 
Table 6 - Fraction of participants in each industry at various stages in the job market

Note: For internships and jobs, the table displays the fraction of participants working in each industry. For invitations, bids, and interviews, the table displays the fraction of invitations, bids, and interviews participants receive from each industry on average. Fractions of invitations, bids, and interviews for internships include all 409 participants while those for jobs include only the 206 participants who did not accept a job at the firm for which they interned.

\begin{tabular}{|c|c|c|c|c|c|c|c|c|c|}
\hline & \multicolumn{3}{|c|}{ MEN } & \multicolumn{3}{|c|}{ WOMEN } & \multicolumn{3}{|c|}{ DIFFERENCE } \\
\hline & Consult. & Finance & Other & Consult. & Finance & Other & Consult. & Finance & Other \\
\hline Job before MBA & $30 \%$ & $29 \%$ & $41 \%$ & $25 \%$ & $30 \%$ & $45 \%$ & $5 \%$ & $-1 \%$ & $-3 \%$ \\
\hline nvitations for internships & $21 \%$ & $55 \%$ & $24 \%$ & $26 \%$ & $32 \%$ & $41 \%$ & $-6 \%$ & $23 \%$ & $-17 \%$ \\
\hline Bids for internships & $21 \%$ & $56 \%$ & $24 \%$ & $32 \%$ & $27 \%$ & $42 \%$ & $-11 \%$ & $29 \%$ & $-18 \%$ \\
\hline Interviews for internships & $21 \%$ & $56 \%$ & $23 \%$ & $27 \%$ & $31 \%$ & $42 \%$ & $-6 \%$ & $24 \%$ & $-19 \%$ \\
\hline Internship & $19 \%$ & $63 \%$ & $19 \%$ & $23 \%$ & $43 \%$ & $34 \%$ & $-4 \%$ & $20 \%$ & $-16 \%$ \\
\hline Dffered job at i & $19 \%$ & $67 \%$ & $14 \%$ & $23 \%$ & $43 \%$ & $34 \%$ & $-4 \%$ & $24 \%$ & $-20 \%$ \\
\hline ccepted job at inter & $14 \%$ & $74 \%$ & $12 \%$ & $25 \%$ & $46 \%$ & $30 \%$ & $-11 \%$ & $28 \%$ & $-18 \%$ \\
\hline nvitations for jobs & $35 \%$ & $38 \%$ & $28 \%$ & $37 \%$ & $25 \%$ & $38 \%$ & $-3 \%$ & $13 \%$ & $-11 \%$ \\
\hline ids & $33 \%$ & $42 \%$ & $25 \%$ & $39 \%$ & $29 \%$ & $32 \%$ & $-6 \%$ & $13 \%$ & $-7 \%$ \\
\hline nte & $34 \%$ & $39 \%$ & $27 \%$ & $36 \%$ & $29 \%$ & $35 \%$ & $-2 \%$ & $10 \%$ & $-8 \%$ \\
\hline ob at gradu & $22 \%$ & $56 \%$ & $22 \%$ & $34 \%$ & $36 \%$ & $30 \%$ & $-12 \%$ & $20 \%$ & $-8 \%$ \\
\hline \multirow[t]{3}{*}{ Present job } & $15 \%$ & $45 \%$ & $40 \%$ & $20 \%$ & $28 \%$ & $52 \%$ & $-5 \%$ & $18 \%$ & $-12 \%$ \\
\hline & \multicolumn{3}{|c|}{ TOURNAMENT } & \multicolumn{3}{|c|}{ PIECE-RATE } & \multicolumn{3}{|c|}{ DIFFERENCE } \\
\hline & Consult. & Finance & Other & Consult. & Finance & Other & Consult. & Finance & Other \\
\hline & & $31 \%$ & $38 \%$ & $26 \%$ & $27 \%$ & $47 \%$ & $5 \%$ & $4 \%$ & $-9 \%$ \\
\hline Invitations & $21 \%$ & $52 \%$ & $27 \%$ & $24 \%$ & $44 \%$ & $33 \%$ & $-2 \%$ & $9 \%$ & $-6 \%$ \\
\hline Bids for intern & $24 \%$ & $51 \%$ & $26 \%$ & $24 \%$ & $44 \%$ & $32 \%$ & $0 \%$ & $6 \%$ & $-6 \%$ \\
\hline Interviews for internships & $23 \%$ & $51 \%$ & $26 \%$ & $23 \%$ & $45 \%$ & $32 \%$ & $-1 \%$ & $6 \%$ & $-5 \%$ \\
\hline Internship & $22 \%$ & $61 \%$ & $17 \%$ & $18 \%$ & $53 \%$ & $30 \%$ & $4 \%$ & $8 \%$ & $-12 \%$ \\
\hline Offered job at in & $25 \%$ & $61 \%$ & $15 \%$ & $15 \%$ & $60 \%$ & $25 \%$ & $10 \%$ & $1 \%$ & $-11 \%$ \\
\hline Accepted job at internship firm & $22 \%$ & $65 \%$ & $14 \%$ & $11 \%$ & $67 \%$ & $22 \%$ & $11 \%$ & $-3 \%$ & $-8 \%$ \\
\hline Invitations for jobs & $32 \%$ & $40 \%$ & $28 \%$ & $39 \%$ & $27 \%$ & $34 \%$ & $-7 \%$ & $13 \%$ & $-6 \%$ \\
\hline Bids for jobs & $33 \%$ & $44 \%$ & $23 \%$ & $36 \%$ & $32 \%$ & $32 \%$ & $-3 \%$ & $12 \%$ & $-9 \%$ \\
\hline Interviews for jobs & $31 \%$ & $44 \%$ & $25 \%$ & $38 \%$ & $27 \%$ & $35 \%$ & $-7 \%$ & $16 \%$ & $-10 \%$ \\
\hline Job at graduation & $28 \%$ & $54 \%$ & $18 \%$ & $24 \%$ & $45 \%$ & $32 \%$ & $4 \%$ & $9 \%$ & $-13 \%$ \\
\hline Present job & $20 \%$ & $43 \%$ & $37 \%$ & $13 \%$ & $37 \%$ & $50 \%$ & $7 \%$ & $6 \%$ & $-13 \%$ \\
\hline
\end{tabular}

allows us to focus instead on the effect of gender and competitiveness on the industry from which participants received invitations, sent bids, and obtained interviews.

Table 6 presents distributions of the three industry categories depending on the participants' gender and whether they chose tournament or piece-rate pay. Specifically, for internships and jobs, the table displays the fraction of participants working in each industry. For invitations and 
interviews, the table displays the average fraction of invitations/interviews that participants receive from firms in each industry. Finally, for bids, the table displays the average fraction of bids that participants sent to firms in each industry. Fractions of invitations, bids, and interviews for internships are based on all 409 participants while those for jobs are based on the 206 participants who did not accept a job at the firm for which they interned.

A gender gap in selection into industries emerges at the very beginning of the MBAs' job market. Compared to men, women receive a smaller fraction of invitations for internships by firms in finance and a larger fraction from firms in consulting and other industries. In a similar vein, women send a smaller fraction of their bids for internships to firms in finance and a larger fraction to firms in consulting and other industries. These differences, particularly the higher fraction of women in other industries, narrow down in latter stages of the job market but remain substantial. The gap between participants who chose tournament pay and those who chose piece-rate pay emerges more slowly. In particular, the difference in the fraction of participants in other industries between those who chose tournament and piece-rate pay grows as the job-market progresses.

To observe a competitiveness industry gap accurately, however, we need to control for other determinants of choosing tournament pay. We do this by running a series of regressions. In all regressions, we include as independent variables gender, choosing tournament over piece-rate pay, the other determinants of choosing tournament pay (see column III of Table 2), and all the remaining control variables from Table 1. We ran regressions for each stage of the job market. For internships and jobs, we estimated a multinomial probit regression with the industry in which each participant worked in as the dependent variable. For invitations, bids, and interviews, we estimated a system of seemingly unrelated regressions with each participant's fraction of invitations/bids/interviews per industry as the dependent variables. As in Table 6, regressions of invitations, bids, and interviews for internships are based on all 409 participants while those for jobs are based on the 206 participants who did not accept a job at their internship firm.

We depict the marginal effect of being female and being competitive on the fraction of participants in each industry in Figure 4. We also show the marginal effect of a one-standard deviation increase in the risk aversion coefficient. It is interesting to compare the emergence of risk aversion and 

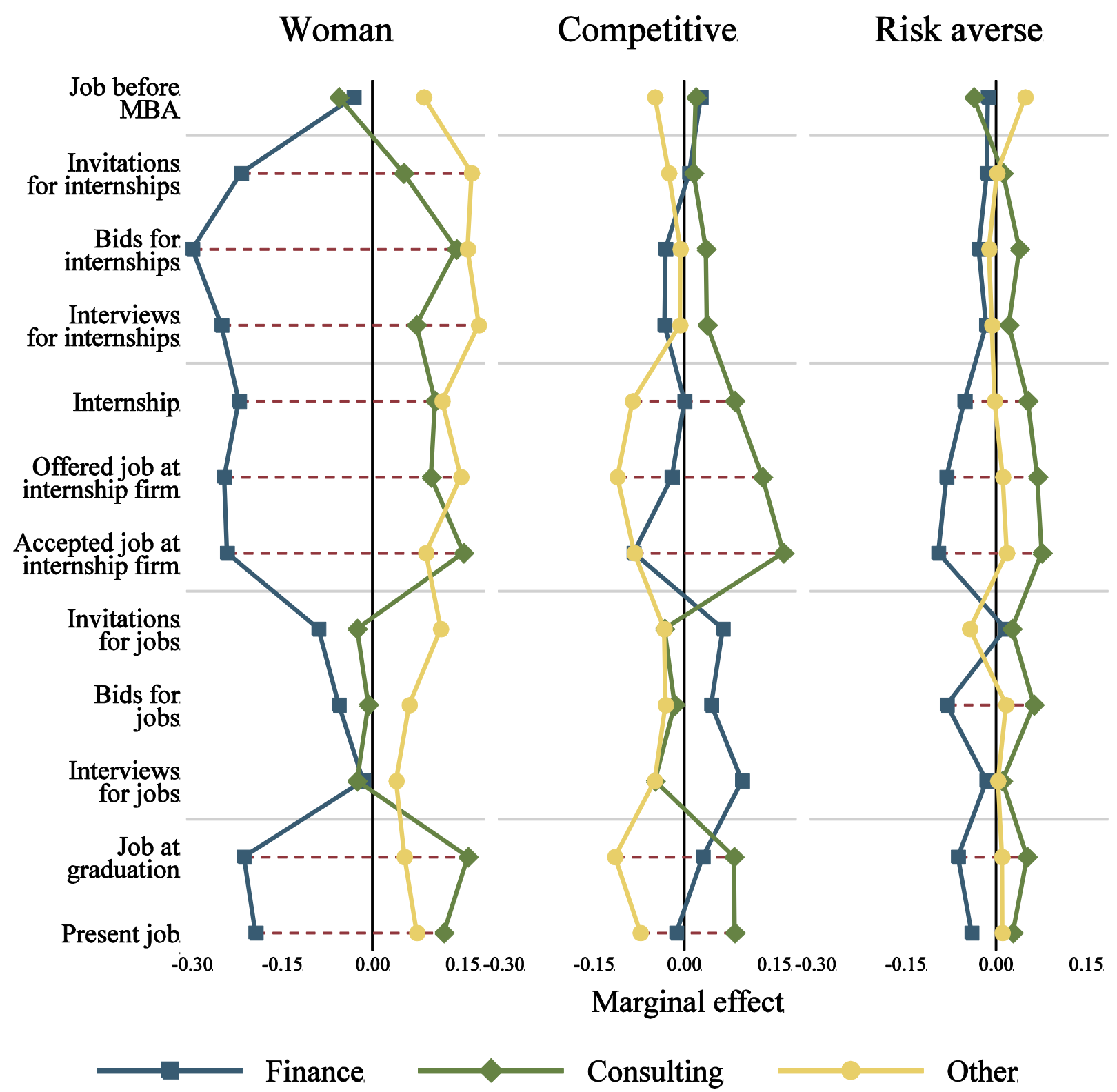

Other

Figure 4 - Marginal effect of gender, competitiveness, and risk aversion, on the fraction of participants in each industry at various stages in the MBA's job market

Note: Marginal effects are estimated from multinomial probit regressions for categorical variables (internships and jobs) and seemingly unrelated linear regressions for ordinal variables (fractions of invitations, bids, and interviews). All regressions include the variables in column III of Table 2 as determinants of choosing tournament pay that are unrelated to competitiveness as well as the remaining variables from Table 1 . The dashed horizontal lines indicate that the marginal effects of the respective independent variable are jointly statistically significant at 0.10 .

competitiveness as predictors of the participants' industry since both are unobservable individual characteristics that exhibit important gender differences. 
As seen in the top row of Figure 4, once we control for other variables, women are 3.0\% less likely to work in finance in the job before their MBA, 5.5\% less likely to work in consulting, and 8.6\% more likely to work in other industries. As soon as the search for internships begins, however, we see that women receive $21.8 \%$ fewer invitations from firms in finance, 5.3\% more invitations from firms in consulting, and $16.5 \%$ more invitations from firms in other industries. Similarly, women send 29.9\% fewer bids to firms in finance, $14.0 \%$ more bids to firms in consulting, and $15.9 \%$ more bids to firms in other industries. These large differences in industry sorting are sustained throughout the internship process and in the jobs taken by participants after graduation. In other words, even after we control for numerous individual characteristics, many of which exhibit gender differences, there is a large gender difference in industry selection that remains unaccounted for. ${ }^{28}$

In contrast to gender, the gap in selection into industries due to competitiveness materializes more gradually. In particular, we do not observe significant differences in the fraction of invitations, bids, or interviews for internships depending on whether participants are competitive or not. The first stage at which competitiveness predicts that participants' industry is once participants decide in which firm to intern. Compared to uncompetitive participants, competitive participants are $8.4 \%$ more likely to intern in consulting and $8.5 \%$ less likely to intern in other industries. Thereafter, the gap between consulting and other industries grows as firms decide whom to make a job offer to and participants decide whether to continue working at their internship firm. The effect of competitiveness wanes once again when participants who do not continue with their internship firm receive invitations, send bids, and obtain interviews only to reemerge once the job market clears and participants have accepted a final job offer.

In summary, the differences in industry sorting that correlate with competitiveness appear to be smaller in stages of the job market where there is less interaction between firms and participants. This pattern suggests that firms are either not interested in selecting based on how competitive individuals are or competitiveness is not a trait that can be identified through the information firms

\footnotetext{
28 The fact that gender differences at stages where firms are selecting (i.e., when giving invitations, interviews, and making offers to interns) are about the same size as those in stages where participants are selecting (i.e., bidding for interviews and accepting internships) suggests that firms are not using gender to discriminate between candidates. However, we cannot reject the possibility that gender differences emerge because participants anticipate discrimination by firms in the different industries and limit their applications to industries where they expect no or even positive discrimination.
} 
have when they extend invitations and decide who to interview. Similarly, the fact that competitiveness does not predict the participants' bids suggests that attributes that make jobs more or less desirable to competitive and uncompetitive participants are not discernable at the applications stage. In other words, information exchanged through the interview process and subsequently while working as interns seems to be crucial for the competitiveness gap in the industry selection to emerge. Interestingly, a similar pattern is observed for the emergence of risk aversion as a predictor of selection into different industries, which suggests that this pattern might be generally present for psychological traits that are typically unobservable.

\section{Discussion}

In this paper, we study whether competitive individuals, as measured by a laboratory experiment, achieve different labor market outcomes than their less competitive counterparts. We find that, among MBA graduates from a prestigious business school, competitive individuals obtain higher earnings at graduation. Importantly, differences in competitiveness account for a significant share of

the gender gap in earnings. In addition, we find that not only are competitive individuals more likely to work in higher-paying industries at graduation, but they are also more likely to remain in these industries several years later.

This paper is related to the growing literature relating attitudes towards competition to gender differences in labor market outcomes (e.g., Zhang, 2013; Buser, Niederle, and Oosterbeek, 2014; Flory, Leibbrandt, and List, 2014; Berge et al., 2015; Kamas and Preston, 2015; Reuben, Wiswall, and Zafar, 2015) and more generally with studies linking traits measured in laboratory settings with actual behavior in the field (e.g., Karlan, 2005; Ashraf, Karlan, and Yin, 2006; Benz and Meier, 2008; Fehr and Leibbrandt, 2011). These studies establish the external validity of the competitiveness traits measured developed by Niederle and Vesterlund (2007), but more importantly, they demonstrate that relevance of competitiveness as a determinant of labor market outcomes. Crucially, the weak correlation between the experimental measure of competitiveness and traditional explanatory variables such as test scores and demographic characteristics indicates that measures of competitiveness provide real added understanding to the analysis of labor markets. 
A potential concern with any study that correlates measures of a particular trait with labor market outcomes is that of reverse causality. For example, if a taste for competition is acquired by working in consulting, then interpretation of the estimates in Tables 3 and 4 is more ambiguous. In this paper, however, we think this is less of a concern for two reasons. First, we measured competitiveness at the beginning of the MBA program, more than one year before participants accepted job offers. Hence, the measure of competitiveness is unaffected by the participants' experiences during their MBA such as exposure to different courses or internships. Second, we find no evidence that competitiveness and the participants' characteristics at the admissions stage are highly correlated, suggesting that differences in competitiveness were not caused by differing experiences before the MBA.

Demonstrating the significance of competitiveness for earnings does open up the question, why do competitive individuals earn more? The most straightforward explanation is that competitive individuals are simply better at the tasks demanded by better-paid jobs. We do not find that competitiveness is correlated with the participants' GPA and GMAT scores, ${ }^{29}$ but it is possible for competitiveness to proxy differences in ability that are not captured by conventional measures. Therefore, a fruitful line of future research would be to study the link between competitiveness and performance in different jobs. Another potential explanation is that competitive individuals might be more likely to negotiate their earnings. In the supplementary materials, we show that there is little support for this explanation in our sample as competitive individuals are equally likely to report that their earnings were the outcome of a successful negotiation. A third explanation is one of tastes. If a majority of people find that working under competitive conditions is inherently distasteful, then there can be a compensating wage differential to work in firms or industries with competitive corporate cultures. ${ }^{30}$ This explanation is consistent with competitive individuals being more common

\footnotetext{
${ }^{29}$ Regressing GPA or GMAT scores on choosing tournament pay and the control variables in column III of Table 2 results in a positive but not statistically significant coefficient for tournament pay ( $p=0.202$ and $p=0.411$ respectively).

30 It is also possible for there to be an interaction between productivity and the environment. Competitive individuals might not be generally more productive, but they might perform better in competitive environments. In fact, a differential response by men and women to tournament incentives and acute stress is often found (e.g., Gneezy, Niederle, and Rustichini, 2003; Angelucci and Córdova. 2014). To our knowledge, this gender difference has yet to be linked to the measure of competitiveness of Niederle and Vesterlund (2007).
} 
in finance and consulting, as these two industries are known for their highly competitive environments (Bertrand, Goldin, and Katz, 2010). In this respect, it would be interesting to identify the specific characteristics of competitive industries that individuals who are classified as competitive find less distasteful. For instance, competitive individuals might be better as managing stress or they might cope better with long and inflexible working hours.

An interesting finding in our study is that differences in industries due to competitiveness appear only in some stages of the job market. ${ }^{31}$ In particular, we see a smaller impact of competitiveness in stages of the job market where there is limited contact between participants and firms. On one hand, this empirical pattern suggests that it is difficult for firms to identify competitive individuals based on the information available to them when they extend interviews and for competitive individuals to identify the specific jobs in which their attitude towards competition gives them a comparative advantage. On the other hand, it raises the question, why does competitiveness predict selection into different industries once participants interact more meaningfully with employers (i.e., after interviewing and working for them)? One possibility is that competitive individuals are more productive in industry-specific tasks but their higher productivity is not evident to employers until they get to talk to them or observe them at work. Another possibility is that participants need firsthand experience with specific firms to evaluate whether they with feel comfortable with the degree of competitiveness in a given firm. In either case, our findings suggest that the matching process in the job market could be improved if firms providing accurate information about their views on competition.

Lastly, we would like to highlight that our sample consists of MBA graduates from one of the top business schools in the country. We think that this is one of the paper's strengths as top business positions is precisely one of the areas where large gender differences persist. Hence, our paper is directly relevant to a population of interest. That being said, our sample is clearly not representative of the general population or even of the average individual in business. Hence, one must be careful when generalizing our findings to other populations. On one hand, gender differences in

\footnotetext{
31 Differing effects of competitiveness at different points in the career of individuals' is consistent with the literature. For instance, Buser, Niederle, and Oosterbeek (2014) find that competitiveness predicts high-school track choices while Reuben, Wiswall, and Zafar (2015) find no relation between competitiveness and major choice in college.
} 
competitiveness might be population specific. For instance, using a representative sample from Norway, Almas et al. (2015) find that gender differences in competitiveness are more pronounced in populations with high socioeconomic status. On the other hand, it is reasonable to presume that competitiveness could have a different effect on earnings in non-business careers. Hence, an important subject matter for future research is to explore the relationship between competitiveness and earnings in other samples.

\section{References}

Almås, Ingvild, Alexander W. Cappelen, Kjell G. Salvanes, Erik Sorensen, and Bertil Tungodden. 2015, "Willingness to Compete: Family Matters." Management Science, forthcoming.

Andersen, Steffen, Seda Ertac, Uri Gneezy, John A. List, and Sandra Maximiano. 2013. “Gender, Competitiveness, and Socialization at a Young Age: Evidence From a Matrilineal and a Patriarchal Society." Review of Economics and Statistics 95 (4): 1438-1443.

Angelucci, Manuela, and Karina Córdova. 2014. "Productivity and Choice Under Stress: Are Men and Women Different?" Working Paper. University of Michigan.

Arulampalam, Wiji, Allison L. Booth, and Mark L. Bryan. 2007. "Is There a Glass Ceiling over Europe? Exploring the Gender Pay Gap across the Wage Distribution." Industrial and Labor Relations Review 60 (2): 163-86.

Ashraf, Nava, Dean Karlan, and Wesley Yin. 2006. "Tying Odysseus to the Mast: Evidence From a Commitment Savings Product in the Philippines." The Quarterly Journal of Economics 121 (2): 635-72.

Azmat, Ghazala, Maia Güell, and Alan Manning. 2006. "Gender Gaps in Unemployment Rates in OECD Countries.” Journal of Labor Economics 24 (1): 1-37.

Babcock, Linda, and Sara Laschever. 2003. Women Don't Ask: Negotiation and the Gender Divide. Princeton, NJ: Princeton University Press.

Balafoutas, Loukas, and Matthias Sutter. 2012. "Affirmative Action Policies Promote Women and Do Not Harm Efficiency in the Laboratory." Science 335 (6068): 579-82.

Baron-Cohen, Simon. 2002. “The Extreme Male Brain Theory of Autism.” Trends in Cognitive Sciences 6 (6): 24854.

Baron-Cohen, Simon, Sally Wheelwright, Jacqueline Hill, Yogini Raste, and Ian Plumb. 2001. "The 'Reading the Mind in the Eyes' Test Revised Version: A Study with Normal Adults, and Adults with Asperger Syndrome or High-Functioning Autism." Journal of Child Psychology and Psychiatry 42 (2): 241-51. 
Benz, Matthias, and Stephan Meier. 2008. "Do People Behave in Experiments as in the Field? - evidence from Donations." Experimental Economics 11 (3): 268-81.

Berg, Joyce, John Dickhaut, and Kevin McCabe. 1995. "Trust, Reciprocity, and Social History." Games and Economic Behavior 10 (1): 122-42.

Berge, Lars Ivar Oppedal, Kjetil Bjorvatn, Armando Jose Garcia Pires, and Bertil Tungodden. 2015. “Competitive in the Lab, Successful in the Field?" Journal of Economic Behavior \& Organization 118: 303-317.

Bertrand, Marianne. 2011. "New Perspectives on Gender." In Handbook of Labor Economics, edited by David Card and Orley Ashenfelter, 4:1543-90. Elsevier B.V.

Bertrand, Marianne, and Kevin F. Hallock. 2001. "The Gender Gap in Top Corporate Jobs." Industrial and Labor Relations Review 55 (1): 3-21.

Bertrand, Marianne, Claudia Goldin, and Lawrence F. Katz. 2010. "Dynamics of the Gender Gap for Young Professionals in the Financial and Corporate Sectors." American Economic Journal: Applied Economics 2 (3): 228-55.

Black, Dan A, Amelia M Haviland, Seth G Sanders, and Lowell J. Taylor. 2008. “Gender Wage Disparities among the Highly Educated." Journal of Human Resources 43 (3): 630-59.

Blau, Francine. 2012. "The Sources of the Gender Pay Gap." In The New Gilded Age: The Critical Inequality Debates of Our Time, edited by David B. Grusky and Tamar Kricheli-Katz, 189-208. Stanford, CA: Stanford University Press.

Booth, Alison, and Patrick Nolen. 2012. “Choosing to Compete: How Different Are Girls and Boys?” Journal of Economic Behavior \& Organization 81 (2): 542-555.

Buser, Thomas, Muriel Niederle, and H. Oosterbeek. 2014. "Gender, Competitiveness, and Career Choices." The Quarterly Journal of Economics 129 (3): 1409-47.

Cason, Timothy N., William A. Masters, and Roman M. Sheremeta. 2010. "Entry into Winner-Take-All and Proportional-Prize Contests: An Experimental Study." Journal of Public Economics 94 (9-10): 604-611.

Cramer, Jan S., Joop Hartog, Nicole Jonker, and Mirjam C. van Praag. 2002. "Low Risk Aversion Encourages the Choice for Entrepreneurship: An Empirical Test of a Truism." Journal of Economic Behavior \& Organization 48 (1): 29-36.

Croson, Rachel, and Uri Gneezy. 2009. “Gender Differences in Preferences.” Journal of Economic Literature 47 (2): 448-74.

Dohmen, Thomas, and Armin Falk. 2011. "Performance Pay and Multidimensional Sorting: Productivity, Preferences, and Gender." American Economic Review 101 (2): 556-590. 
Dreber, Anna, Emma von Essen, and Eva Ranehill. 2014. "Gender and Competition in Adolescence: Task Matters." Experimental Economics 17 (1): 154-72.

Equilar. 2015. "200 Highest-Paid CE0 Rankings.” Retrieved from http://www.equilar.com/nytimes200.

Eccles, Jacquelynne S. 1994. "Understanding women's educational and occupational choices." Psychology of Women Quarterly 18 (4): 585-609.

Exley, Christine L., Muriel Niederle, and Lise Vesterlund. 2015. “Knowing When to Ask: The Cost of Leaning In.” Working Paper. Harvard Business School.

Fehr, Ernst, and Andreas Leibbrandt. 2011. "A Field Study on Cooperativeness and Impatience in the Tragedy of the Commons." Journal of Public Economics 95 (9-10): 1144-55.

Flory, J. A., A. Leibbrandt, and J. A. List. 2015. “Do Competitive Workplaces Deter Female Workers? A LargeScale Natural Field Experiment on Job Entry Decisions." The Review of Economic Studies 82 (1): 122-155.

Frederick, Shane. 2005. "Cognitive Reflection and Decision Making." Journal of Economic Perspectives 19 (4): $25-42$.

Gneezy, Uri, Kenneth L. Leonard, and John A. List. 2009. “Gender Differences in Competition: Evidence From a Matrilineal and a Patriarchal Society." Econometrica 77 (5): 1637-1664.

Gneezy, Uri, Muriel Niederle, and Aldo Rustichini. 2003. "Performance in Competitive Environments: Gender Differences." The Quarterly Journal of Economics 118 (3): 1049-74.

Goleman, Daniel, and Richard Boyatzis. 2008. "Social intelligence and the biology of leadership." Harvard Business Review 86 (9): 74-81.

Gupta, Nabanita Datta, Anders Poulsen, and Marie-Claire Villeval. 2013. "Gender Matching and Competitiveness: Experimental Evidence." Economic Inquiry 51 (1): 816-835.

Hartog, Joop, Ada Ferrer-i-Carbonell, and Nicole Jonker. 2002. "Linking Measured Risk Aversion to Individual Characteristics." Kyklos 55 (1): 3-26.

Healy, Andrew, and Jennifer Pate. 2011. “Can Teams Help to Close the Gender Competition Gap?” The Economic Journal 121 (555): 1192-1204.

Holt, Charles A, and Susan K Laury. 2002. "Risk Aversion and Incentive Effects." American Economic Review 92 (5): 1644-1655.

Isaac, R. Mark, James M Walker, and Susan H. Thomas. 1984. "Divergent Evidence on Free Riding: An Experimental Examination of Possible Explanations." Public Choice 43 (2): 113-149.

Kamas, Linda, and Anne Preston. 2010. “Are Women Really Less Competitive than Men?” Working Paper. Santa Clara University. 
Kamas, Linda, and Anne Preston. 2015. “Competing with Confidence: The Ticket to Labor Market Success for College-Educated Women." Working Paper. Santa Clara University.

Karlan, Dean S. 2005. "Using Experimental Economics to Measure Social Capital and Predict Financial Decisions." American Economic Review 95 (5): 1688-99.

Leibbrandt, Andreas, and John A. List. 2015. “Do Women Avoid Salary Negotiations? Evidence from a LargeScale Natural Field Experiment." Management Science 61 (9): 2016-24.

Lent, Robert W, and Gail Hackett. 1987. "Career Self-Efficacy: Empirical Status and Future Directions." Journal of Vocational Behavior 30 (3): 347-382.

Niederle, Muriel, Carmit Segal, and Lise Vesterlund. 2013. "How Costly Is Diversity? Affirmative Action in Light of Gender Differences in Competitiveness." Management Science 59 (1): 1-16.

Niederle, Muriel, and Lise Vesterlund. 2007. “Do Women Shy Away From Competition? Do Men Compete Too Much?" The Quarterly Journal of Economics 122 (3): 1067-1101.

Niederle, Muriel, and Lise Vesterlund. 2011. “Gender and Competition.” Annual Review of Economics 3 (1): 60130.

Reuben, Ernesto, Paola Sapienza, and Luigi Zingales. 2008. "A Description of the Chicago-Templeton Longitudinal Study." University of Chicago.

Reuben, Ernesto, Pedro Rey-Biel, Paola Sapienza, and Luigi Zingales. 2012. "The Emergence of Male Leadership in Competitive Environments." Journal of Economic Behavior \& Organization 83 (1): 111-17.

Reuben, Ernesto, Paola Sapienza, and Luigi Zingales. 2014. “How Stereotypes Impair Women's Careers in Science." Proceedings of the National Academy of Sciences 111 (12): 4403-8.

Reuben, Ernesto, Matthew Wiswall, and Basit Zafar. 2015. "Preferences and Biases in Educational Choices and Labour Market Expectations: Shrinking the Black Box of Gender." The Economic Journal, forthcoming.

Saks, Raven E., and Stephen H Shore. 2005. "Risk and Career Choice." The B.E. Journal of Economic Analysis \& Policy 5 (1).

Schwarzer, Ralf, Judith Bassler, Patricia Kwiatek, Kerstin Schroder, and Jian Xin Zhang. 1997. "The Assessment of Optimistic Self-Beliefs: Comparison of the German, Spanish, and Chinese Versions of the General SelfEfficacy Scale." Applied Psychology 46 (1): 69-88.

Sherer, Mark, James E. Maddux, Blaise Mercandante, Steven Prentice-Dunn, Beth Jacobs, and Ronald W. Rogers. 1982. "The self-efficacy scale: Construction and validation." Psychological Reports 51 (2): 663-71.

Small, Deborah A, Michele Gelfand, Linda Babcock, and Hilary Gettman. 2007. "Who Goes to the Bargaining Table? The Influence of Gender and Framing on the Initiation of Negotiation." Journal of Personality and Social Psychology 93 (4): 600-13. 
Stajkovic, Alexander D., and Fred Luthans. 1998. "Self-Efficacy and Work-Related Performance: A MetaAnalysis." Psychological Bulletin 124 (2): 240-261.

Toplak, Maggie E., Richard F. West, and Keith E. Stanovich. 2011. “The Cognitive Reflection Test as a Predictor of Performance on Heuristics-and-Biases Tasks." Memory \& Cognition 39 (7): 1275-89.

Thoma, Volker, Elliott White, Asha Panigrahi, Vanessa Strowger, and Irina Anderson. 2015. “Good Thinking or Gut Feeling? Cognitive Reflection and Intuition in Traders, Bankers and Financial Non-Experts." PLOS ONE 10 (4): e0123202.

Wolfers, Justin. 2006. "Diagnosing Discrimination: Stock Returns and CEO Gender." Journal of the European Economic Association 4 (2-3): 531-41.

Wozniak, David, William T. Harbaugh, and Ulrich Mayr. 2014. “The Menstrual Cycle and Performance Feedback Alter Gender Differences in Competitive Choices." Journal of Labor Economics 32 (1): 161-98.

Zafar, Basit. 2013. "College Major Choice and the Gender Gap." Journal of Human Resources 48 (3): 545-95.

Zhang, Y. Jane. 2013. "Can Experimental Economics Explain Competitive Behavior Outside the Lab?" SSRN Working Paper \#2292929. 